(C)2019, Elsevier. Licensed under the Creative Commons Attribution-NonCommercialNoDerivatives 4.0 International http://creativecommons.org/about/downloads

c) $(1) \odot$ 


\title{
How Organizational Structure Transforms Risky Innovations into Performance - A Computer
}

\section{Simulation $^{1}$}

Matthias G. Will ${ }^{2}$, Mousa Al-kfairy ${ }^{3}$ and Robert B. Mellor ${ }^{3}$ *

2) Martin Luther University Halle-Wittenberg, Germany and 3) Kingston University, London, UK.

* Corresponding author on r.mellor@kingston.ac.uk

In: Simulation Modelling Practice and Theory (2019).

\begin{abstract}
This paper investigates the mutual interdependencies between organizational architectures, decision making and performance. Through applying agency-based Monte-Carlo simulations, we reveal how three types of organizational structure (hierarchical, polyarchical and hybrid) aggregate innovations on the micro level into corporate performance. By considering three different initial project portfolios (incremental innovations, innovations with spillover effects and innovations that have to overcome a critical mass), we analyze which organizational architectures may be superior regarding selecting good projects, avoiding collective myopia and overcoming organizational inertia. Results suggest that in a risky environment, firms with rigid hierarchies can achieve a much higher performance than horizontally organized firms even when the quality of the decision-making by managers is poor. Results also highlight the dangers involved in erecting a more hybrid-type organization because such an organization might become over-challenged and unable to handle risky innovations adequately. Finally, we discuss how firms could be structured to increase performance and to minimize risks.
\end{abstract}

\section{Key Words:}

Formal Model, Monte-Carlo Simulations, Regression Analysis

\footnotetext{
${ }^{1}$ This paper develops the preliminary discussion started by the conference paper Will et al, (2017a) and develops this to reveal four surprising but noteworthy features of organizational architectures.
} 


\section{Introduction}

The past decade has seen a rise in the opinion that hierarchical firms exhibit inferior corporate performance compared to firms with a more horizontal form of organization (for a discussion see e.g. Benner \& Tushman, 2003, pp. 252-253 as well as Keupp et al., 2012), and examples often quoted include cases of team structures (Foss \& Lindenberg, 2012; Foss \& Lindenberg, 2013; Lindenberg \& Foss, 2011; Reagans et al., 2016) or open network-like forms of organizing (Cheng et al., 2014; Felin \& Zenger, 2014; Sheremata, 2004; Tushman, 2015; West \& Bogers, 2013; Wolter \& Veloso, 2008). The core arguments against hierarchical decision-making include that such organizations constrain the proliferation of beneficial innovations because communication and decision making is restricted (Davis et al., 2009; DeCanio et al., 2000). These debates imply that an increased horizontal structure, like teams or open network-like 'hybrid” architectures, would result in a better economic performance.

However, such claims may be misleading if organizations have to choose between risky innovations, especially where these are costly (Mellor, 2019). In such a world, a core challenge of the organization is to adopt "good" innovations (e. g. good innovations have more benefits than costs for the organization) and reject "bad" ones (e. g. projects that cause higher costs than benefits, which in turn could be due to poor implementation, spiraling costs or other negative outcomes; examples are presented by Khanna et al., 2016; van der Panne et al., 2003; Priem et al., 2012; and Stevens and Burley, 1997). As Baregheh et al, (2009) highlight, the term "innovation" has many meanings and connotations, making it quite difficult to present a unique definition. But within a for-profit firm, the organization's inherent logic reveals a striking similarity that focuses on the functionality within the organization: every change in the processes, products or managerial practices that increases the corporate value is a "good" innovation, while changes that reduce the value are "bad" ones.

Choosing innovations from risky portfolios in an appropriate way depends not only on the decisionmaker's (usually managers and their subordinates, committees or teams) skill in evaluating an innovation, but also upon the organizational architecture, which has a reverberating and indeed determining effect on the organization's performance because it defines how risky decisions are made and implemented (Sah \& Stiglitz, 1985; as well as Sah \& Stiglitz, 1986). Surprisingly, previous studies considering a risky environment with bounded rationality (Simon, 1982), have found that traditional 
hierarchical firms may exhibit superior performance when compared to more horizontal organizations (Argyres \& Silverman, 2004; Csazsar, 2012; Knudsen \& Levinthal, 2007). Conversely, when considering horizontal organizations, bounded rationality may even result in collective myopia (Knudsen \& Srikanth, 2014; Mellor 2015a, Mellor 2015b; Sydow et al., 2009), which in turn has even further negative consequences for the organization.

Put briefly; one problem is poor decision making, but inappropriate organizational architectures aggregate this into low performance, and a better understanding of organizational architectures may uncover quite counter-intuitive results compared to simple ad-hoc theories regarding the pros and cons of horizontal, hierarchical and hybrid organizing (Ethiraj \& Leveninthal, 2004b). This may also explain why organizations may perform badly after becoming more team-friendly, hybrid and/or ambidextrous. Moreover, it is utopian to believe that one single architecture can achieve optimal results in all environments and developmental stages and indeed, as Argyres \& Silverman (2004) and Siggelkow \& Rivkin (2005) argue, different designs may be differentially appropriate, depending on the professionality, size and complexity of the organization and its relationship with its immediate environment. That view notwithstanding, the question about what an appropriate combination of hierarchical and horizontal structures is for a firm (regarding e.g. risks of innovations and the degree of bounded rationality) remains an open question (see e.g. Christensen \& Knudsen, 2010; Csaszar, 2013; Csaszar \& Eggers, 2013; Knudsen \& Srikanth, 2014). While acknowledging that many other approaches are feasible, here we present a purely mathematical approach on this theme in the tradition of Sah \& Stiglitz (1985) as well as Sah \& Stiglitz (1986). Furthermore, the Stata regression analyses allow this work to give more accurate results than hitherto available.

Many scholars in the field of organizational ambidexterity and innovation management argue that hybrid structures would achieve a higher performance compared to traditional hierarchical firms (for the alleged superior performance of teams see Reagans et al., 2016; Young-Hyman, 2016; for the alleged superiority of ambidextrous organizations see Benner \& Tushman, 2003; Benner \& Tushman, 2015; and O’Reilly III \& Tushman, 2013; and for quite similar arguments see the debate on open innovations (Cheng et al., 2014; Felin \& Zenger, 2014; West \& Bogers, 2013; Wolter \& Veloso, 2008). However, contributions in the field of organizational architectures reveal that hybrid structures often achieve only average 
performance (see for example Knudsen \& Levinthal, 2007). These realizations led some authors e.g. Christensen \& Knudsen (2010) to argue that an appropriate combination of poly- and hierarchical structures may create a better corporate architecture despite the fact that single parts are imperfect (because of bounded rationality), and Knudsen \& Levinthal (2007) contributed to this discussion by pointing out that the strength of hybrid organizations is the ability to select good projects through polyarchical structures plus the implementation of successful projects through hierarchies. As a consequence, the respective strengths of both systems can be combined and their respective weaknesses (thought of as the difficulty in implementing common strategies in polyarchies, versus the selection of a diverse portfolio in a hierarchy), is reduced.

Thus the first contribution of this paper concerns how organizational structures can be designed to achieve better outcomes despite bounded rationality (Csaszar, 2012; Csaszar, 2013), and our findings indicate that hybrid structures may exhibit problematic side-effects regarding the handling of commission (first order) and omission (second order) errors (Knudsen \& Srikanth, 2014), thus explaining why companies may for example hesitate to implement team structures, despite their positive motivational effects on organizational behavior.

Secondly, a clever combination of polyarchical and hierarchical elements in an organization can cause surprising outcomes; Ethiraj \& Leveninthal (2004b) argue that simple ad hoc assumptions regarding the performance of hierarchies and polyarchies may be wrong and that at least one wide-spread assumption about hierarchies, namely that they have difficulties in adapting to rapid environmental changes (see for example Birkinshaw et al., 2008 as well as Subramanian \& Nilakanta, 1996) may be contentious because even highly centralized hierarchies can change rapidly as long as the command structure promotes good decisions and fast implementations. In contrast to hierarchies, polyarchies - like markets - are often seen as highly flexible and able to handle even radical changes and these agile characteristics are positive in turbulent times. However, dysfunctional feedback in polyarchies can prevent adaptation and result in chaos. Thus, one could speculate that there does not have to be a natural superiority of one economic system, and that good performance depends on the structures of decision-making and implementation (as proposed by Knudsen \& Srikanth, 2014). Indeed, it was Schumpeter (1942, 2003) who argued that it is not only small entrepreneurs who cause "creative destruction", but also that large organizations with 
appropriate structures can promote innovations en masse. Our findings emphasize that hierarchies may be superior compared to market-like polyarchies because the latter may collapse in an environment with risky innovations, due to taking up too many poor innovations.

Thirdly, a commonly-held view is that there are benefits in reducing coordination costs (or the critical mass of an organization that has to be overcome in order to implement innovations, see Sydow et al., 2009; Mellor, 2018; Nickerson \& Zenger, 2002) and that poor performance can be attributed to managers failing to do so. However, our findings highlight that under particular circumstances, high coordination costs (and a high critical mass) can be beneficial for organizations because these parameters make it more difficult for risky innovation to pervade the organization. Surprisingly, this is especially true for hybrid organizations because these organizations often fail in ousting bad innovations. This provides support for the idea of Knudsen \& Srikanth (2014) that hybrid organizations bear an architectural disadvantage when collective myopia may cause a kind of herd behavior and end up ruining the whole organization.

Fourthly, we differentiate not only between hierarchical, polyarchical and hybrid architectures but we also take up the call for further research by Csaszar \& Eggers (2013) about how organizational architectures leverage risk. By including a range of initial project portfolios with different levels of risks, we estimate the effect of each organizational structure on the leverage of risk, revealing under which conditions reducing risks and increasing performance are complementary and under which conditions a tradeoff emerges between risk and performance.

In this work we use an agency approach to simulate a range of different ideal-typical architectures in order to achieve a comprehensive range of test factors (Davis et al., 2007). Results were then additionally analyzed by a second independent round of regression analyses. As a consequence of this rigorous approach, underlying and hitherto unsuspected systematic patterns were revealed about how organizational architecture aggregates the selection of risky innovations into organizational performance. The investigation includes a range of three different initial portfolios: Firstly, innovations with only incremental effects, secondly, innovations that have spillover effects and thus may end in collective myopia, and thirdly, innovations that require a critical mass of supporters to be implemented, 
otherwise the organization would stay on its inertial path. The next section summarizes our formal models and the simulation approach used.

\section{Simulating the Impact of Innovative Behavior on Corporate Performance}

This section investigates the dichotomy of polyarchies and hierarchies (see Sah \& Stiglitz 1985, 1986) and also different hybrid structures (see e.g. Christensen \& Knudsen, 2010; Knudson \& Levinthal, 2007; Siggelkow \& Rivkin, 2005) by employing an agency-based simulation. The approach follows that of Sah \& Stiglitz $(1985,1986)$ in that decision makers choose innovations blindly from an initial portfolio containing projects with "negative” as well as "positive” consequences for organizational performance. Typically, innovators are often convinced that their innovations will create high profits, but in reality, and for a wide variety of reasons, innovations often fail (van der Panne et al., 2003; Stevens \& Burley, 1997), incurring costs and wasting scarce resources (Khanna et al., 2016; Priem et al., 2012). In an ex post consideration, adopting these innovations should not have been attempted, however, ex ante, such assessments are clearly difficult (Berg, 2016). This is followed by an analysis of how different organizational architectures mitigate risky innovations if decision makers are imperfect in evaluating the quality of an innovation.

Across all permutations of organizational architectures (as well as the spectrum of initial project portfolio), the basic rule of the decision-maker is: implement an innovation if the expected gain is positive and do not implement the innovation if the expected value is negative, although an individual's rationality is limited due to limited and unreliable information, limited capacities to evaluate and process information, or a limited amount of time for making a decision (Simon, 1982). Because of this, decisionmakers cannot evaluate the full consequences of an innovation, and may make errors of the first order (error of commission) and second order (error of omission) (see Sah \& Stiglitz 1985, 1986), meaning that for the economic performance of an organization, accepting good innovations increases performance, rejecting bad ones avoids losses, rejecting good projects has opportunity costs (omission error) in a world with competition, and accepting bad projects creates losses (commission error).

\subsection{Varying the type of innovations}


First, we assume that decision-makers have to choose projects from differing portfolios of initial innovations and because of this, wrong decisions (e. g. omission and commission errors) have different organizational outcomes and these outcomes are partially determined by the organizational architecture.

2.1.1 Innovations with incremental effects: This simulation is reminiscent of the previous approaches of Sah \& Stiglitz (1985, 1986) as well as Christensen \& Knudsen (2010), Csaszar (2013), Knudson \& Levinthal (2007) and Siggelkow \& Rivkin (2005) in that after the decision regarding the implementation of an innovation has been made, the innovation's real (cash) value becomes apparent with regard to determining the omission and commission mistakes. This means that a decision-maker evaluates the innovation and implements or rejects the innovation accordingly, leading to four possible outcomes; accept a "good” innovation, reject a "bad” one, accept "bad” innovations (commission error), or reject “good” innovations (omission error). Clearly, accepting a "good” project means the organization will gain by this decision according to the real cash value that reveals itself afterward and in the case of accepting a "bad" project, this innovation will also reveal its cash value after the decision and this value reduces the corporate performance. Rejecting good and bad projects bears opportunity costs and these effects can be revealed by comparing the average performance of different architectures and, by applying additional regression, we get a more profound picture of the mitigating effects of organizational architectures (see section findings).

2.1.2 Innovations with spillover effects: The second project portfolio assumes that colleagues can follow innovators and implement the innovation just as the innovator did. In the case that peers follow the innovator, we have a spillover. For example, one employee comes up with an organizational innovation (for example how to handle customer feedback) and their peers can decide whether they follow the innovator or not. By doing so, we differentiate between two variations of our model (see the section on findings). In the first variation, we follow the idea of Knudsen \& Srikanth (2014, p. 416) that in organizations "flawed mental models may never be corrected in coordinated exploration because of enduring epistemic interdependence. This is in sharp contrast to models of unitary search in which epistemic interdependence is absent, and correction of mental models is possible." As a consequence, 
organizations may suffer from collective myopia because individuals tend to follow their peers instead of critically questioning their suggestions. The dynamic effects of collective myopia can significantly reinforce the innovations' effects on organizational performance, both for the better as well as for the worse. In the case of a poor project, joint myopia may cause overly heavy negative consequences for the organization. However, and in the case of a good project, joint myopia can lead to extremely positive consequences, as indeed Acs et al. (2009), De Bondt (1997) and Harhoff et al., (2003) highlight.

In the second model variation, peers individually evaluate the quality of a project and after this assessment, they decide whether to follow or not to follow. According to the quality of their assessment, they can accept good projects, reject bad ones, or make omission and commission errors.

In addition to this and compared to incremental innovations, the implementation of such an innovation does not have clearly defined boundaries of potential gains and losses because in our model the spread of the innovation within the organization depends on the coordination costs that arise when innovators talk to their peers and try to convince them to be followers. How this is done mathematically is summarized in section 3.

2.1.3 Innovations requiring a critical mass: In this instance the implementation of an innovation requires the support of a critical mass within the organization, otherwise the organization would remain trapped within its own inertia (see also Sydow et al., 2009, Mellor, 2015a and Mellor, 2015b). This could be, for example, where the organization must implement new technologies in the whole value creation process; the re/up-skilling of staff, networks with stakeholders, including suppliers, may have to be changed and the organizational culture and management style adapted accordingly (Mellor, 2003 and see also Slater et al., 2013). For example, Chen et al. (2013), Harvey (2014) and Rogers (1983) all observed that in the case of radical innovations, project initiators may have to convince the relevant part of the organization to implement the project. However, reaching such a critical mass requires a complex coordination between employees and indeed this may overexert the whole organization. This is simulated in our approach because innovators have to balance expected gains of an innovation (again, they can err ex ante whether it is a good or bad innovation) with the coordination costs that arise for convincing sufficient colleagues. The simulations presented include where peers simply follow the 
innovators because of joint myopia, and where employees evaluate the innovation first and make a decision to follow afterwards.

Against the backdrop of collective myopia (Knudsen \& Srikanth, 2014), the necessity for achieving a critical mass may obviate the negative effects incurred by following innovators with poor innovations (as long as the critical threshold is not reached). At first sight this contradicts claims by researchers in the field of organizational culture and organizational inertia (e.g. Slater et al., 2013), who argue that reducing the critical mass would be beneficial for implementing innovations and changes, however, it is in agreement with Kreps (1990) who argued that critical mass may also guarantee stability in a noisy environment (for a similar argument see also Nickerson \& Zenger, 2002).

\subsection{Varying the architecture of the organization}

The above three types of innovations can be simulated in different organizational architectures that range from pure polyarchies to pure hierarchies as two extreme forms of economic organizing. Figures 1-3 illustrate the three basic forms; polyarchy, hierarchy and a hybrid organization, and these are described in the following sections:

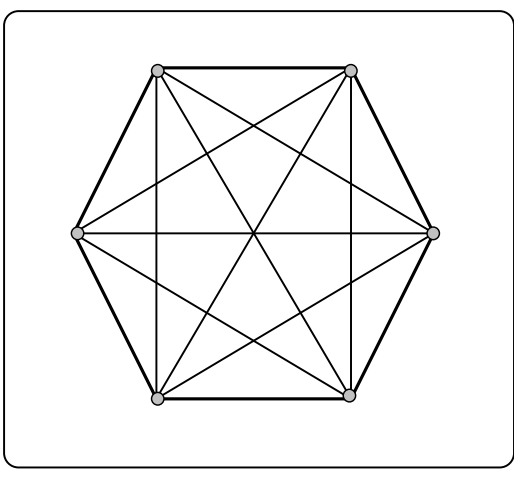

Figure 1: A Polyarchy (own figure)

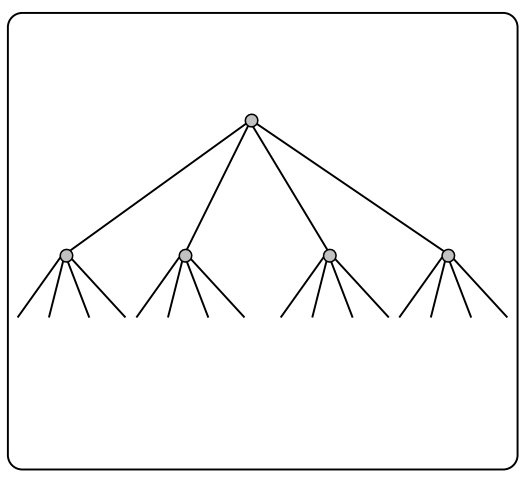

Figure 2: A Hierarchical Firm (own figure)

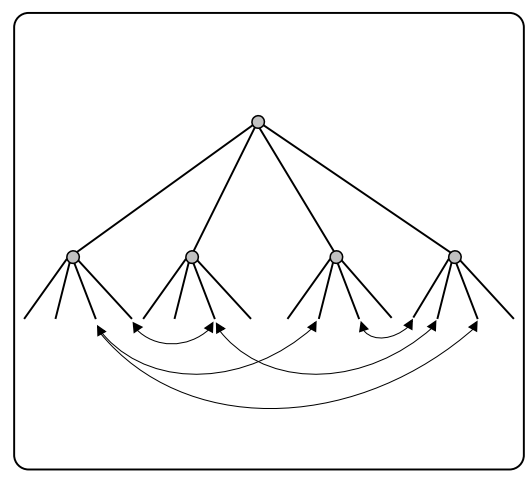

Figure 3: A Hybird Organization (own figure)

2.2.1 Polyarchical organizations (Figure 1): In a polyarchy, agents can communicate with each other and make their decisions regarding the implementation of an innovation independently. Such a marketlike structure can also be described as a network of equal peers with similar powers, where all members are "nearest neighbor”. In such a polyarchy, agents are free to implement innovations individually (Sah 
\& Stiglitz, 1985, 1986) or they can convince their peers to act with them, for example in the case of innovations with spillover effects and/or of projects that require a critical mass.

In the case of innovations with spillover effects, the members of a polyarchy can tell their peers about their ideas. However, convincing those peers is associated with coordination costs (Sah \& Stiglitz, 1985, 1986; Reagans et al., 2016; Wolter \& Veloso, 2008); at the very least, the agents have to spend time and effort to explain their ideas, and for more complex projects, followers may have to even be given instruction and supervision, etc. These coordination costs have different effects: in the case of a "good" innovation, the coordination costs reduce the marginal gains of every additionally convinced peer. In the case of "bad" innovations, however, the coordination costs increase the damage of joint myopia because coordination costs increase the negative effects of herd behavior.

Regarding innovations requiring a critical mass, our simulations assume that organizations have different critical points that make the difference between inertia and penetration. Some organizations might exist that can easily overcome their organizational inertia, while other organizations have to address the broad majority of its members to make a sustainable change (Garicano \& Rayo, 2016; Slater et al., 2013; and Utterback, 1994). We model that innovators have to convince their peers, which require that they "invest" coordination costs to spread the idea up to and beyond the critical mass because project initiators have to invest time and possibly other resources, for lobbying and spreading the innovation within the organization. If initiators manage to convince a number that reaches the critical mass, then the project becomes established. Of course, some innovations might have an expected gain that is lower than the total coordination costs that would be necessary to reach the critical amount. In such a case, innovations will "die" and the organization will stay in its inertia. Similar is the case of innovations with spillover effect; convincing colleagues about "good" projects reduces the total gains, while spreading "bad” innovations increases the total damage.

2.2.2 Hierarchical organizations (Figure 2): In this case, managers on different hierarchical levels have different executive functions and different decision-making powers. Below these managers are employees that are bound by instruction i.e. they are subordinates and assigned to one department governed by a manager. In such an organization, communication and decision-making follow clear 
rules: decision processes are organized hierarchically and subordinates have to follow the instructions given by their managers. Bottom-up communication is possible, but the hierarchy works as a gatekeeper, meaning that any bottom-up proposals are subject to a managerial decision. Furthermore, that implementation without managerial acceptance is not possible. Such a hierarchical organization is the opposite of a polyarchy. While the former is organized vertically, the latter is organized horizontally. Thus, these two organizations illustrate two extreme forms of economic organizing, and because of this, we use these two extreme forms as reference points for the concept of the hybrid organization, which is practically-speaking, more relevant (see below).

Regarding incremental innovations within a hierarchy, subordinates on the lower level can recommend projects to choose (Sah \& Stiglitz, 1985, 1986), but they need the approval from their superiors, and without this approval they cannot implement the project. To approve the proposed innovation, the manager must review the quality of the project in order to prevent poor projects (i.e. judged as resulting in a negative cash value) from being implemented. However, managers can also make bad decisions (for a model theoretical contribution see Sah \& Stiglitz, 1985, 1986; and for a general argument see Jensen, 1988, Berg, 2016 and Garicano \& Rayo, 2016), for example, they can reject “good” projects (type one error or commission error), and they can also accept "bad” projects (type two error or omission error). In our simulations, we model organizations with one, two and three hierarchical levels. In the case of a two-level hierarchy, the managers on the lowest level have to make a decision, and then their superior also has to make a decision. Only when both accept the project, the subordinate can implement it. Similarly, in the case with three levels, the managers at level $1,2 \& 3$ all have to accept the idea otherwise the proposed project is rejected.

In the case of an innovation with spillover effects, we follow the idea of a straight hierarchy with bottomup communication and top-down decision-making power. So, the subordinate initiator has to convince management gatekeepers about the quality of the proposed project before it can be implemented. Thus, the hierarchy prevents joint myopia (Knudsen \& Srikanth, 2014). However, superiors make the decision for the whole organization whereupon the subordinates have to implement those projects accordingly, and independently of if it is a "good" or "bad" innovation; it only matters that the managers were convinced by the initiator. 
In a hierarchy, initiators need the approval of their superiors in order to implement innovations that have to overcome a critical mass. Nevertheless, critical mass still has to be attained to achieve implementation. Thus, superiors have to weigh the expected gains from the project against the coordination costs needed for informing sufficient subordinates to reach critical mass within the organization. Because of this, they only implement projects if they expect that the gains of the innovations are higher than the coordination costs that are necessary to implement the innovation. As before, superiors may unwittingly approve 'bad' projects, where after the coordination costs incurred serve to increase the damage done by the project. As before, this can be expanded to additional levels of management with two and three levels of hierarchies.

2.2.3 Hybrid organizations (Figure 3): Hybrid architectures are a combination of polyarchical and hierarchical structures (see Christensen \& Knudsen, 2010; Knudson \& Levinthal, 2007 and Siggelkow \& Rivkin, 2005). Such organizations have a hierarchy, but the hierarchy does not have absolute control over information flow and decision rights. For example, in a hybrid organization, subordinates may be connected with peers from other departments through team or similar structures, enabling communication and decision-making in both vertical (hierarchical) and horizontal directions (YoungHyman, 2016), and possibly including that subordinates can work around the hierarchy gate-keeping. Consequently, the hierarchy loses absolute decision control.

Regarding the simulation of incremental projects in hybrid organizations, subordinates can choose if they make the decision by themselves or if they prefer the hierarchy to decide. In our agent-based approaches, subordinates prefer making decision by themselves because they are convinced by their projects. Decision processes for these kinds of projects take place in hybrid organizations just like in polyarchies i.e. on a horizontal level; therefore, we do not present simulations of incremental projects in hybrid organizations, because the findings are similar to polyarchies. Nonetheless, future approaches might consider, for example, how subordinates’ risk aversion may influence to what extent subordinates prefer their superiors to make decisions.

In the case of innovations with spillover effects in a hybrid organization, project initiators can spread their innovations by convincing their superiors, or they can use horizontal structures that emerge 
through, for example, cross-departmental teams between hierarchical levels where project initiators use the option that maximizes the absolute expected gain of their projects. Because of bounded rationality, they choose the option that has a higher expected value regarding the implementation of the project. This means, if they expect that their superiors will support their project, they choose the hierarchy. However, if they expect that the chance of it spreading through the organization is higher, they will choose their horizontal network.

Finally, in a hybrid organization, innovators must choose if they use the hierarchy for overcoming the critical mass, or if they try to use horizontal structures for spreading their ideas. We assume that innovators compare the expected gains by contrasting the hierarchy vs. horizontal paths and they choose the alternative that increases the expected gains. As we will highlight, the hybrid structures make it possible for innovators to overcome the critical mass constraints more easily than compared to polyarchies and hierarchies. However, this may not be an advantage if innovations are risky and if coordination costs increase the damage caused by poor innovations.

\section{Methodology and Simulation Design}

The advantages of using an in silico approach include that the interdependencies between project selection, organizational structure and performance can be precisely and independently controlled. Against the backdrop of the formulae given below, agency-based approaches were simulated by a stochastic Monte Carlo simulation. Methods are as described by Chib \& Greenberg (1996) (a more recent overview is given by Davis et al. 2007 and by Robinson, 2014. For a general framework and for the application of Monte Carlo approaches in organizational research, see e.g. Almirall \& CasadesusMasanell, 2010; Chang \& Harrington, 2000; Cowan et al., 2007; Davis et al., 2009; and DeCanio et al., 2000; as well as Ethiraj \& Levinthal, 2004a).

Summarizing the ideas of our simulation (see Table 1 for an overview and 3.1 for details), random project portfolios $\left(b_{i}\right)$ on the individual level were obtained from different normal distributions on the organizational level that result in negative ("bad") or positive ("good") innovations. This represents the main input into all organization architectures simulated. These portfolios were used across all three 
organization architectures with some adaptations based on the architecture under investigation. The least complicated models are the ones for incremental innovations in polyarchies and hierarchies.

Decision quality $(\pi)$ of managers and peers was generated from uniform distributions, which represents the second core parameter adapted for most organizations. This parameter determines managers' decisions ( $\rho_{i}$ with 0 : reject a project, or 1: accept a project). Further adaptations were introduced for different organization architectures to reflect the decision-making process e.g. the additional coordination costs incurred by persuading others. This parameter is added for our models with spillover effects and the ones that require a critical mass. For a detailed description of the models with innovations that have spillover effects in polyarchies, hierarchies and hybrids, see the corresponding equations (4) to (11) in 3.1. Finally, we investigated how overcoming a critical mass influences organizational performance. Again, we simulate these effects in polyarchies, hierarchies and hybrids. For details see equations (12) until (17).

\begin{tabular}{|l|l|l|l|}
\hline & Polyarchy & Hierarchy & hybrid organizations \\
\hline Incremental innova- & Equation 1 and figure & $\begin{array}{l}\text { Equations 2 \& 3 and } \\
\text { figure 4 }\end{array}$ & $\begin{array}{l}\text { The same as poly- } \\
\text { archies with incremen- } \\
\text { tal innovations }\end{array}$ \\
\hline Innovations with spill- & $\begin{array}{l}\text { Equations 4, 5, 6 \& 7 } \\
\text { over effects }\end{array}$ & Equation 8 and figure & Equations 9, 10 \& 11 \\
\hline Innovations that have & Equations 12 \& 13 and & Equation 14 and fig- & Equations 15, 16 \& 17 \\
to overcome a critical & $\begin{array}{l}\text { figure 7 } \\
\text { mass }\end{array}$ & ure 7 & and figure 7 \\
\hline
\end{tabular}

Table 1: Co-ordination table showing a summary of which equations are connected to which experimental combinations

\subsection{Methodology and Simulation Design}

This section sets the foundation for modeling the aggregation of agents' decisions, and explains the formulas used. In all models, the underlying decision rule is the same: Decision-makers (and their followers) implement (or delegate implementation) when they expect an innovation to have a positive 
value, and not if they expect economic damage. However, this decision is made under conditions of bounded rationality:

3.1.1. Incremental innovations within a polyarchy: In a similar fashion to Sah \& Stiglitz $(1985,1986)$, members can immediately implement the project they choose in a polyarchy (Figure 1). As a consequence, the impact of such a choice for the whole polyarchy is the sum of all individuals' chosen projects:

$$
b=\sum_{i=1}^{n} b_{i}
$$

We assume that the agents' chosen projects can be represented by a cash value $b_{i}$ with $b_{i} \sim N\left(\mu, \sigma^{2}\right)$ where $\mu$ is the medium benefit per agent (e. g. the agent's individual performance for implementing the innovation), and $\sigma^{2}$ is the variance. Regarding the innovation-generating process $b_{i}$, we assume innovations can have either negative, or positive cash value. For every organization, we simulated a mean $\mu$ and standard deviation $\sigma$ (while the mean $\mu$ and standard deviation $\sigma$ is randomly obtained from uniform distribution). These two parameters define the average cash value of every innovation in this organization. In a second step, we generate the parameter $b_{i}$ randomly from normal distribution $b_{i} \sim N\left(\mu, \sigma^{2}\right)$ for each employee. Then, agents implement the projects directly because they assume a positive innovation according to their bounded rationality (Sah \& Stiglitz 1985 and 1986). Finally, the innovation’s real cash value unveils ex post to measure the organization's performance.

This approach enables us to simulate organizations that have different patterns of innovative behavior: from organizations with a high positive mean to organizations with an extremely negative mean of the innovations' cash value on the one side and organizations with a low variance of the innovations' cash value to a high variance of the value. For this simulation, the dataset includes 1,000 polyarchies with 500 organization members (employees) each. The US Census Bureau (USCB, 2016) shows that the limit of 500 employees covers $99.7 \%$ of all firms.

We simulate these parameters for all other organizations and their organizational members in a similar way. We ran additional simulations with 25, 50, 100, 250 and 10,000 employees in an organization to reveal if any size effects exist but found that such effects do not exist and because of this, only the findings using 500 are presented here. In the following sections we summarize how our other simulations differ from this basis approach. 
3.1.2. Incremental innovations within a hierarchy: The following function is obtained for an organization with one hierarchical level, where the parameter $\rho_{i}$ is the superior's approval:

$$
b=\sum_{i=1}^{n}\left\{\begin{array}{c}
b_{i}, \text { if } \rho_{i}=\text { yes } \\
0, \text { if } \rho_{i}=\text { no }
\end{array}\right.
$$

The model considers the quality of managerial decisions, where the same $b_{i}$ from above is used (incremental innovations within a polyarchy), to ensure consistency between all models. The quality of the managers' decision can be built into the formula as follows:

$$
b=\sum_{i=1}^{n}\left\{\begin{array}{c}
b_{i}, \text { if } \rho_{i}=y e s \mid b_{i}>0 \text { with } \pi \text { or if } b_{i}<0 \text { with }(1-\pi) \\
0, \text { if } \rho_{i}=\text { no }
\end{array}\right.
$$

Where the parameter $\pi$ describes the quality of the manager's decision, that is: with a probability of $\pi$, the decision is correct, meaning acceptance of good project and rejection of bad ones. Equally the probability of making a wrong decision is $(1-\pi)$. The quality of the managers' decision-making is defined for every firm with $\pi \sim$ unif $(0.5 ; 1)$. This means that the quality of the management within the firm is equal, and spans between organizations from the extreme $\pi=0.5$ (managers make decisions as they would flip a coin, as in Sah \& Stiglitz, 1985, 1986) until $\pi=1$, where managers possess perfect knowledge and decision-making skills (e. g. perfect rationality). Thus, the probability of acceptance is a conditional probability depending on the value of $\pi$, and the ratio between good and bad projects, meaning that $\rho_{i}$ uses binary coding of either zero (no) for rejection, or one (yes) for acceptance. Values of $\pi$ lower than 0.5 are excluded a priori in this work because such managers would systematically prefer bad projects to good ones and, while anecdotally such managers may exist, we assume they would soon leave the organization. However, it is known that under circumstances of managers acting "with guile", the damage is only slowly cumulative over several years (Mellor, 2016).

Formula (3) illustrates the case of an organization with one hierarchical level, but clearly one can take organizations into account that have more e.g. two and three levels of hierarchies. This was modeled using the logical AND operator, so $\rho_{i}$ for all manager in $n$ hierarchies' organization must be set to one (approval) in order to proceed with a project. This indicates that the probability that $n$ managers decide to implement a good project will be $\pi^{h}$ where $h$ is the number of hierarchies (managers). In case of accepting poor projects, we need $h$ managers making the same bad decision in a row, resulting in a probability of $(1-\pi)^{h}$. Therefore, the probability that an innovation is implemented - independent of its 
quality - is in a hierarchy with $h$ levels: $\left(\pi^{h}+(1-\pi)^{h}\right)$. The probability that such a $h$-level hierarchy does not implement either a good nor a bad project is $1-\left(\pi^{h}+(1-\pi)^{h}\right)$.

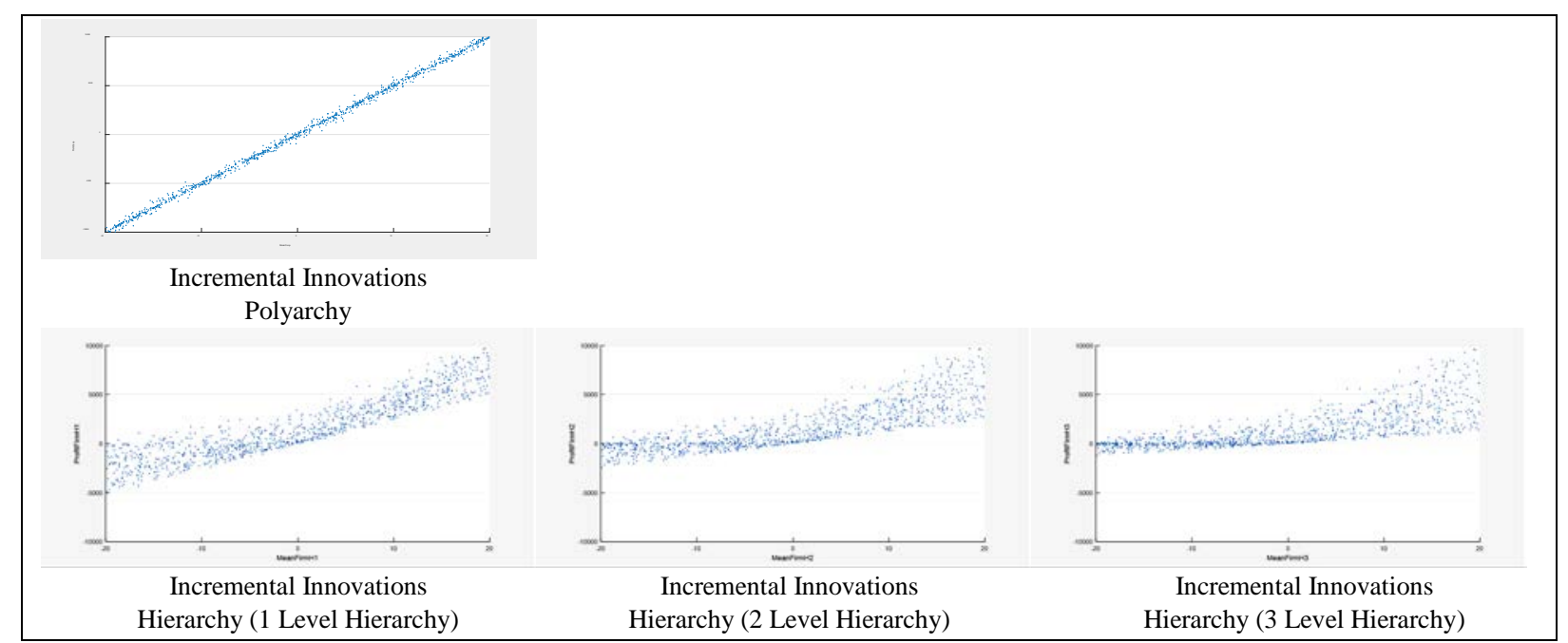

Figure 4: Plots of the effect of incremental innovations on organization performance in polyarchies and hierarchical organizations (own figure)

3.1.3. Incremental projects within hybrid organizations: Regarding the simulation of incremental projects in hybrid organizations, subordinates could choose if they make the decision by themselves or if they want that the hierarchy makes a decision. Considering our agent-based approaches, subordinates would prefer making decision by themselves because of being convinced by their projects. Decision processes for these kinds of projects take place in hybrid organizations just as in polyarchies: on a horizontal level. Therefore, we do not simulate incremental projects in hybrid organizations here because the findings are similar to polyarchies. However, future approaches might consider, for example, how subordinates' risk aversion may influence to what extent subordinates prefer to pass on decisions to their superiors.

3.1.4. Innovations with spillover effects in a polyarchy: In line with ideas on coordinating collective innovative behavior (Sah \& Stiglitz, 1985, 1986; Reagans et al., 2016; Wolter \& Veloso, 2008), we assume that coordination costs increase in a linear fashion with every convinced peer, that is, convincing the first person invokes a cost of $t$, and convincing the second one causes $2 t$, etc. In the basic model that we use as a reference point, we assume that peers simply follow the initiator because of joint myopia. 
An extension of this model involves that peers do not behave as a herd and are able to individually evaluate the quality of the project and make a decision as to whether they follow or not. This is encapsulated in equation (7).

In addition, we assume for the basic model that agents behave in a rational way i.e. that agents do not try to convince additional peers if that leads to marginal coordination costs that are in excess of the expected marginal gains made by convincing that additional person. Thus, in the case of a good innovation $\left(b_{i}>0\right)$ we get for the polyarchy as a sum of the initial agent's effects $b_{i}$ and the effects of their followers:

$$
b=\sum_{i=1}^{n}\left(b_{i}+0.5 b_{i}^{2} / t\right)
$$

Formula 4 compounds the initial portfolio $b_{i}$ for the initiator, and the effect of following the initiator: $0.5 b_{i}^{2} / t$. This effect is calculated as the area of a triangle between the initial project's cash value $b_{i}$ till the last peer $b_{i} / t$, who implements this project (this is illustrated by the green area in Figure 5). In formula (4) the parameter $t$ describes the coordination cost that is necessary to convince and to instruct another peer. This cost was randomly obtained from uniform distribution using $t \sim$ unif (min; max) on an organizational level (e. g. for every organization member, the cost $t$ are identical, while the costs differ between organizations).

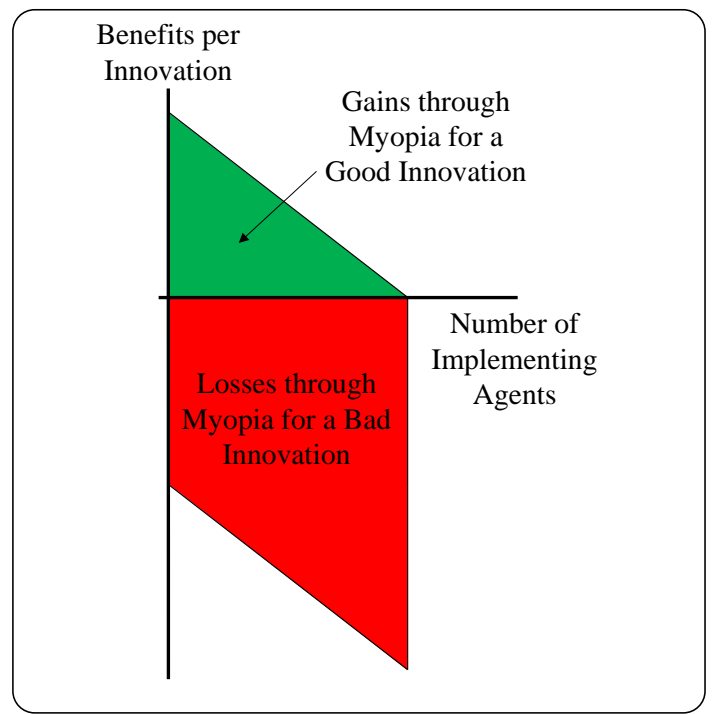

Figure 5: Gains and losses in the case of innovations with spillover effects (green area: myopia in the case of a good innovation; red area: myopia in the case of a bad innovation) (own figure)

Formula (4) can also be extended to cover situations where projects would have negative cash values, giving: 


$$
b=\sum_{i=1}^{n}\left(b_{i}-b_{i}^{2} / t-0.5 b_{i}^{2} / t\right)=\sum_{i=1}^{n}\left(b_{i}-1.5 b_{i}^{2} / t\right)
$$

Formula (5) describes the situation where the initiator and peers implement 'bad' innovations $\left(b_{i}<0\right)$, while increasing the damage that these projects inflict through accruing additional coordination costs as well. Because of this we get the factor 1.5 for a quadrilateral (the red area) plus a triangle represented by the green area (i.e. non-congruent portfolios, as illustrated by the red area in Figure 5). The quadrilateral represents the total damage done by all peers who follows the "bad" innovation, where the triangle represents the total coordination costs that emerge through convincing peers about bad innovations. In case of bad innovations, the adopters mistakenly assume that the bad innovation would be a good innovation, an effect of collective myopia (Knudsen \& Srikanth, 2014), thus for simplicity we assume that they are only wrong regarding the algebraic sign of the innovation's cash value. ${ }^{2}$ Using formula (4) and (5), the effects of 'good' and 'bad' innovations for the whole organization can be given as:

$$
b=\sum_{i=1}^{n}\left\{\begin{array}{l}
b_{i}+0.5 b_{i}^{2} / t, \text { if } b_{i}>0 \\
b_{i}-1.5 b_{i}^{2} / t, \text { if } b_{i}<0
\end{array}\right.
$$

As formula 6 highlights, the coordination costs form a natural boundary that restricts the spillover effects that emerge, when peers follow the initiator.

A further level of sophistication is the consideration that followers might not just follow initiators, but rather independently evaluate the quality of the innovation. They can also choose if they want to become adopters or not (Jensen, 1988). These evaluations at the individual level result in a damping effect. For example, in the case of 'bad' innovations, initiators may cause less harm because peers can assess the quality and choose not to adopt. Errors of the second order are also possible: With 'bad' innovations the result would be some (but still less) damage for the polyarchy. Conversely, in the case of a good innovation, initiators may only be able to convince few peers to adopt because of errors of the first order. These two effects can be combined to account for the quality of the peers' decision-making $\pi$ :

\footnotetext{
${ }^{2}$ A different model design could be to assume that actors do not know the absolute cash value of an innovation and have to make prognoses about the volume of the cash value. In such a model where decision is related to expectation, the respective total gains (in the case of a good project) and respective total losses (in the case of a bad innovation) would obviously differ as compared to the above approach. However, if we assume a normal distribution around the "real" cash value for simulating such expectations, then we would on average get function (6) for the organization as a whole (but not for the single innovation). In addition, such a simulation regarding expectations would not change the finding that in the case of following bad projects, the consequences are much worse than the consequences of following a good project with the same absolute cash value. Because of this, we simply assume that people are wrong regarding the algebraic sign.
} 


$$
b=\sum_{i=1}^{n}\left\{\begin{array}{r}
b_{i}+0.5 \pi b_{i}^{2} / t, \text { if } b_{i}>0 \\
b_{i}-1.5(1-\pi) b_{i}^{2} / t, \text { if } b_{i}<0
\end{array}\right.
$$

3.1.5. Innovations with spillover effects in a hierarchy: As described above, the subordinate initiator has to convince management gatekeepers about the quality of the proposed project before it can be implemented. Thus, the hierarchy prevents herd behavior, and superiors make the decision for the whole organization whereupon the subordinates have to implement those projects accordingly. In this case, it is assumed that managers exhibit bounded rationality, and halt implementation at the point where marginal coordination costs begin to nullify the gains incurred by each additional subordinate implementing the project. In this approach, the coordination costs encompass the costs incurred to explain the proposed innovations to subordinates as well as other implementation costs. The following function can be derived for a firm with one managerial decision-making instance:

$$
b=\sum_{i=1}^{n}\left\{\begin{aligned}
b_{i}+0.5 b_{i}^{2} / t, \text { if } \rho_{i} & =\text { yes } \mid b_{i}>0 \text { with } \pi \\
b_{i}-1.5 b_{i}^{2} / t, \text { if } \rho_{i} & =\text { yes } \mid b_{i}<0 \text { with }(1-\pi) \\
0, \text { if } \rho_{i} & =\text { no }
\end{aligned}\right.
$$

This can be continued for organizations with more than one level (i.e. two and three levels) of managerial decision-making authority. The underlying logic for a multi-level hierarchy is similar to the above hierarchy with incremental innovations: The probability that $h$ managers decide to implement a good innovation will be $\pi^{\mathrm{h}}$ where $h$ is the number of hierarchies (managers). In the case of accepting poor projects, we need $n$ managers making the same bad decision in a row. So we get a probability of $(1-\pi)^{\mathrm{h}}$. The same values of $b_{i}$ were used in all cases, ensuring the comparability of models for each architecture modelled.

3.1.6. Innovations with spillover effects in a hybrid organization: Innovators can convince their superiors, or they can use horizontal structures for overcoming the hierarchy. They use the option that maximizes the absolute expected gain of their projects. For a hybrid organization with one level of hierarchy, we get as a combination of horizontal and hierarchical structures:

$$
b=\sum_{i=1}^{n}\left\{\begin{array}{cl}
b_{i}+0.5 b_{i}^{2} / t, & \text { if } \left.\rho_{i}=\text { yes and } E \text { (hier. }\right)>\mathrm{E}(\text { hori. }) \mid b_{i}>0 \text { with } \pi \\
b_{i}-1.5 b_{i}^{2} / t, & \text { if } \rho_{i}=\text { yes and } E(\text { hier. })>\mathrm{E}(\text { hori. }) \mid b_{i}<0 \text { with }(1-\pi) \\
b_{i}+0.5 \pi b_{i}^{2} / t, & \text { if } E(\text { hier. })<E(\text { hori. }) \mid b_{i}>0 \\
b_{i}-1.5(1-\pi) b_{i}^{2} / t, \quad \text { if } E(\text { hier. })<E(\text { hori. }) \mid b_{i}<0 \text { and }\left|b_{i}\right|-c t / 1-\pi>0 & \text { and } c / 1-\pi<\text { Size Organization } \\
0, \quad \text { otherwise }
\end{array}\right.
$$


In formula (9), the first two parts define the effect if innovators decide to use the authority (the first one is in the case of accepting a good innovation and the second one it is accepting a bad innovation). The third and fourth parts of (9) represent the situation if the innovator spreads ideas horizontally (the third one illustrates the case if the innovator spreads a good idea and the peers evaluate it, and the fourth one highlights the case of a bad innovation and peers evaluate it). The terms $\mathrm{E}$ (hier.) $>\mathrm{E}$ (hori.) and $\mathrm{E}$ (hier. $)<\mathrm{E}$ (hori. ), respectively, describe how project initiators compare the expected effects of using the hierarchy (presented by E(hier. ) - see below) with the expected impact they can achieve via using horizontal structures (E(hori.) see below). Briefly, project initiators use hierarchical structures when their superiors approve, and where the absolute value attained through the hierarchy is higher than the value of using horizontal structures would be. If the effect of the horizontal structure is more beneficial in absolute terms, then they would spread their innovation horizontally and would not use the hierarchy (E(hier. ) < E(hori. )). Thus, innovation initiators look for that path which increases the expected gains of their innovation.

We simulated these decisions for hybrid organizations with one, two and three hierarchical levels. In case of one hierarchical level, the expected value of the hierarchy is calculated using:

$$
E(\text { hier. })=\left\{\begin{array}{c}
b_{i}+0.5 b_{i}^{2} / t, \text { if } \rho_{i}=y e s \mid b_{i}>0 \text { with } \pi \\
b_{i}-1.5 b_{i}^{2} / t, \text { if } \rho_{i}=\text { yes } \mid b_{i}<0 \text { with }(1-\pi) \\
0, \text { if } \rho_{i}=\text { no }
\end{array}\right.
$$

while the expected value for the horizontal structure is determined by:

$$
E(\text { hori. })=\left\{\begin{array}{r}
b_{i}+0.5 \pi b_{i}^{2} / t, \text { if } b_{i}>0 \\
b_{i}-1.5(1-\pi) b_{i}^{2} / t, \text { if } b_{i}<0
\end{array}\right.
$$

Again, the underlying logic for a multi-level hierarchy is similar to the above 'hierarchy with incremental projects': The probability that $n$ managers decide to implement a good innovation will be $\pi^{h}$, where $h$ is the number of hierarchies. In the case of accepting poor innovations, we need $n$ managers making the same bad decision in a row, resulting in a probability of $(1-\pi)^{h}$.

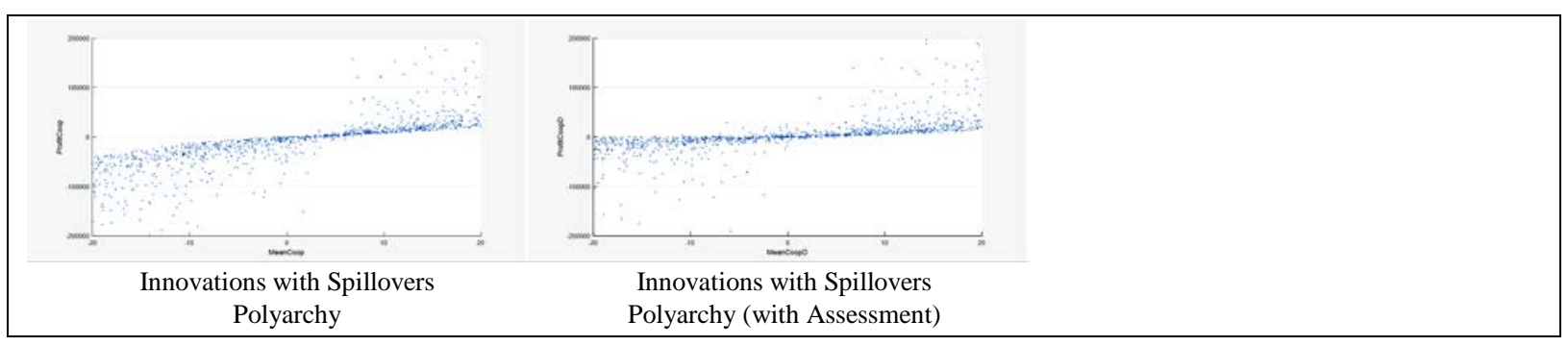




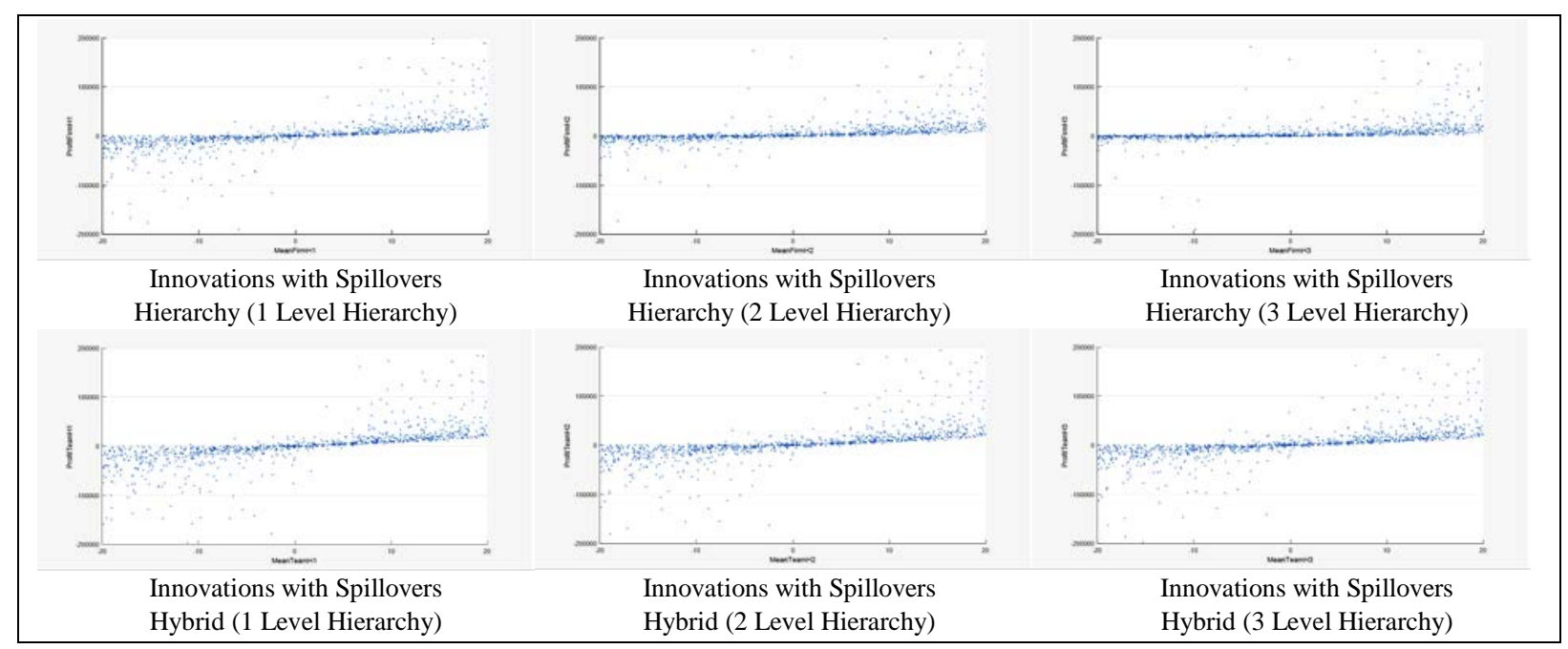

Figure 6: Plots of the effects of innovations with spillover effects on organization performance in polyarchies, hierarchies and hybrids (own figure)

\subsubsection{Innovations requiring a critical mass in polyarchical, hierarchical and hybrid structures:}

The simulations presented here assume that organizations have different critical points that make the difference between inertia and penetration and that these points are between $0 \%$ and $100 \%$. Consequently, the critical mass is defined as $c \sim u n i f(0 ; 1)$ for every organization (within the organization the critical mass is constant for all innovations, and between organizations this parameter differs).The existence of a critical mass point has different implications for the modelling of the three organizational structures:

(a) Innovations requiring a critical mass in a polyarchy: Here innovators have to convince their peers, which requires that they "invest” coordination costs to spread the idea up to and beyond the critical mass. Again, assuming (bounded) rational actors, innovators will only try to convince peers, if the expected gains are greater than the costs needed to reach the critical point. However, it could be equally so that initiators are trying to convince their peers to implement a negative innovation, whereupon these coordination costs must be added to the damage caused. This is expressed in formula 12:

$$
b=\sum_{i=1}^{n}\left\{\begin{array}{r}
b_{i}-c t, \text { if }\left|b_{i}\right|-c t>0 \\
0, \text { if }\left|b_{i}\right|-c t<0
\end{array}\right.
$$

The term ct defines the coordination costs that have to be invested to convince the critical mass. As before, the effect of peer-evaluation on the quality of the project can be taken into account. This results in the following formula:

$$
b=\sum_{i=1}^{n}\left\{\begin{array}{c}
b_{i}-c t / \pi, \text { if } b_{i}>0 \text { and } b_{i}-c t / \pi>0 \text { and } c / \pi<\text { Size of the Organization } \\
b_{i}-c t / 1-\pi, \text { if } b_{i}<0 \text { and }\left|b_{i}\right|-c t / 1-\pi>0 \text { and } c / 1-\pi<\text { Size of the Organization } . \\
0, \text { otherwise }
\end{array}\right.
$$


Formula (13) adjusts the critical mass according to the quality of the decision $\pi$. This means that, if innovators have a good innovation, they have to convince more people compared to the situation without individual evaluations (cf. the situation presented in Formula 12), and the same also holds for the situation when initiators unwittingly want to convince their peers to adopt a 'bad' innovation. Thus, in both cases, larger total coordination costs are necessary for implementing innovations because only some of the peers follow, each according to their own assessment of the innovation. Furthermore, the adjusted critical mass can reach a larger number than the size of the organization and in such a situation the project simply cannot be implemented because there is a quantitatively insufficient population within the organization.

(b) Innovations requiring a critical mass in a hierarchy: For an organization with one level of hierarchy, we derive:

$$
b=\sum_{i=1}^{n}\left\{\begin{aligned}
b_{i}-c t, \text { if } \rho_{i} & =y e s \mid b_{i}-c t>0 \text { and } b_{i}>0 \text { with } \pi \\
b_{i}-c t, & \text { if } \rho_{i}=y e s|| b_{i} \mid-c t>0 \text { and } b_{i}<0 \text { with }(1-\pi) \\
0, \text { if } \rho_{i} & =\text { no } \mid \text { otherwise }
\end{aligned}\right.
$$

Equation 14 shows that managers make the decision about if an innovation should be implemented or not, taking into account not only their evaluation regarding the quality of the innovation, but also upon total coordination cost $c t$ that is necessary for convincing at least the critical mass, implying in turn that the total coordination costs must be expected to be lower than the expected gains. Otherwise managers would not assign the implementation even if they expect a good innovation.

(c) Innovations requiring a critical mass in a hybrid architecture: As in the case of innovations with spillover effects, innovators can spread their ideas by convincing their superiors, or they can use alternative horizontal structures. If we assume that innovators use the option that maximizes the expected absolute gain of their innovation (i.e. spreads their projects as widely as possible), then the organization with hybrid structures and one level of hierarchy can be modeled by:

$$
b=\sum_{i=1}^{n}\left\{\begin{array}{c}
\left.b_{i}-c t, \text { if } \rho_{i}=y e s \text { and } E \text { (hier. }\right)>E(\text { hori. }) \mid b_{i}-c t>0 \text { and } b_{i}>0 \text { with } \pi \\
b_{i}-c t, \text { if } \rho_{i}=y e s \text { and } E(\text { hier. })>E(\text { hori. })|| b_{i} \mid-c t>0 \text { and } b_{i}<0 \text { with }(1-\pi) \\
\left.b_{i}-c t / \pi, \text { if } E(\text { hier. })<E \text { (hori. }\right) \mid b_{i}>0 \text { and } b_{i}-c t / \pi>0 \text { and } c / \pi<\text { Size Org. } \\
\left.b_{i}-c t / 1-\pi, \text { if } E \text { (hier. }\right)<E \text { (hori.) } \mid b_{i}<0 \text { and }\left|b_{i}\right|-c t / 1-\pi>0 \text { and } c / 1-\pi<\text { Size Org. } . \\
0, \text { otherwise }
\end{array}\right.
$$

In formula (15), the first two functions calculate the effects if innovators should choose their superiors, and the third and fourth function measure the effect if they choose horizontal structures for spreading 
their ideas. Again, project initiators compare the benefits of using horizontal structures with the effects of using the hierarchy. This is illustrated by the terms $\mathrm{E}$ (hier.) $>\mathrm{E}$ (hori. ), and $\mathrm{E}$ (hier.) $<\mathrm{E}$ (hori.). In the case of just one hierarchical level, the expected value of the hierarchy is calculated through

$$
E(\text { hier. })=\left\{\begin{array}{rl}
\left|b_{i}\right|-c t, \rho_{i} & =\text { yesif } b_{i}>0 \text { with } \pi \text { orif } b_{i}<0 \text { with }(1-\pi) \\
0, \rho_{i} & =\text { no }
\end{array} .\right.
$$

The expected value for the horizontal structure can be determined by

$$
E \text { (hori.) }=\left\{\begin{array}{c}
b_{i}-c t / \pi, \quad b_{i}>0 \text { and } b_{i}-\frac{c t}{\pi}>0 \text { and } c / \pi<\text { Size Org. } \\
\left|b_{i}\right|-\frac{c t}{\pi}, \& b_{i}<0 \text { and }\left|b_{i}\right|-\frac{c t}{1-\pi}>0 \text { and } c / 1-\pi<\text { Size Org. } \\
0, \text { otherwise }
\end{array}\right.
$$

And this was simulated for structures in hybrid organizations with one, two and three hierarchical levels.

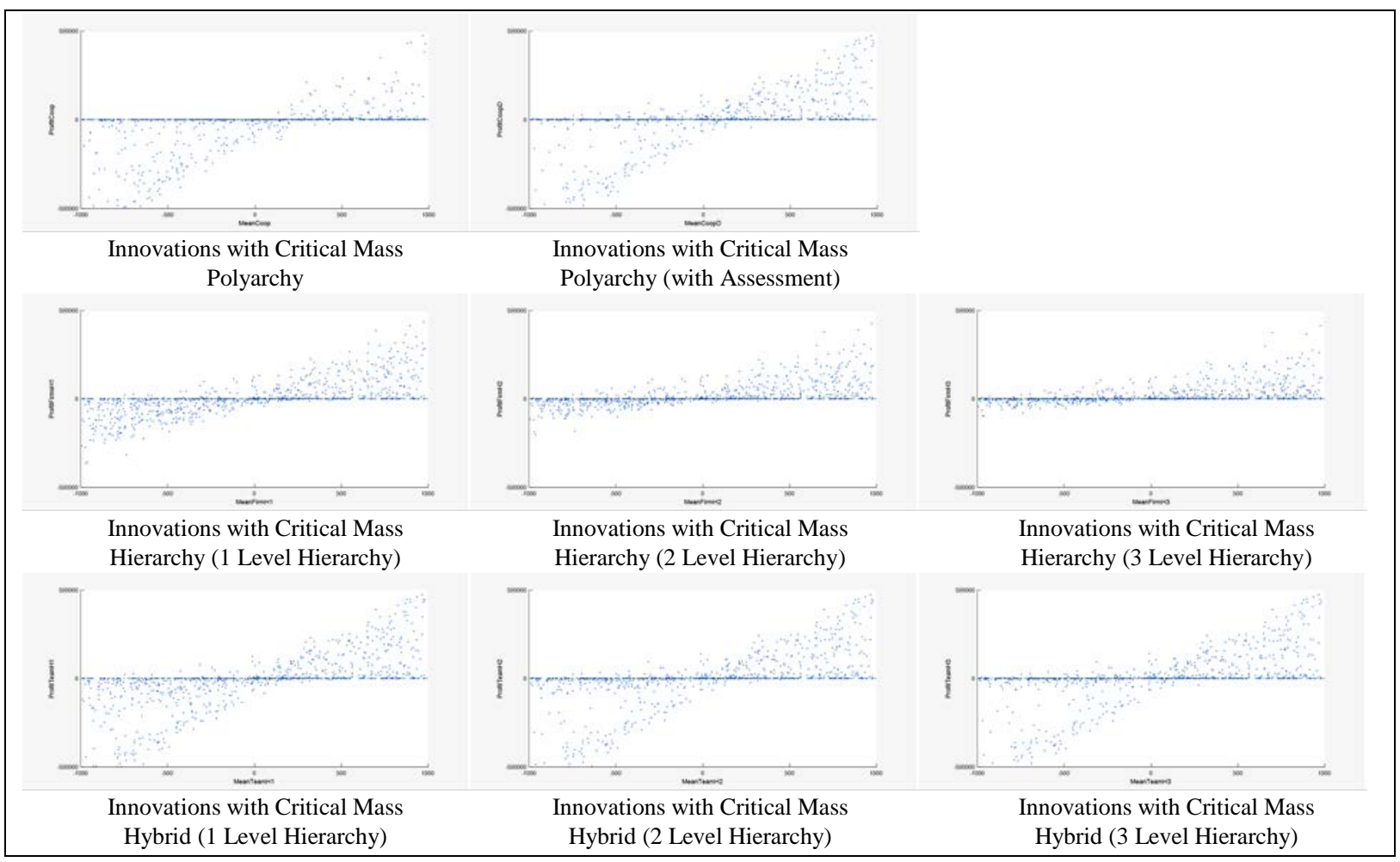

Figure 7: Plots of the effect of innovations that have to overcome a critical mass on organization performance in polyarchies, hierarchies and hybrids (own figure)

\subsection{Simulation methods and defining the parameters and running the simulations}

The parameters used in the Monte Carlo simulations are summarized in Table 1 below. Simulations were performed in Microsoft Excel and Maple 18 (www.maplesoft.com). Tools giving similar results include MatLab and MiniTab. Regression coefficients from the plots were determined using Stata. 
Table A-T1: Overview of the parametrization used for the simulations

\begin{tabular}{|c|c|c|c|c|c|c|c|c|c|c|c|c|}
\hline \multirow[t]{2}{*}{$\begin{array}{l}\text { Innovations with Incremental } \\
\text { Effects }\end{array}$} & \multirow[t]{2}{*}{$\begin{array}{l}\text { Number of } \\
\text { Organizations }\end{array}$} & \multirow[t]{2}{*}{$\begin{array}{l}\text { Number of } \\
\text { Employees } \\
\text { per Org. }\end{array}$} & \multicolumn{2}{|c|}{$\begin{array}{l}\text { Mean of the } \\
\text { Employees' } \\
\text { Innovations } \\
\text { per } \\
\text { Organization }\end{array}$} & \multicolumn{2}{|c|}{$\begin{array}{l}\text { Standard } \\
\text { Deviation of } \\
\text { the } \\
\text { Employees' } \\
\text { Innovation }\end{array}$} & \multicolumn{2}{|c|}{$\begin{array}{l}\text { Quality of } \\
\text { Decision for } \\
\text { Assessing } \\
\text { Innovations }\end{array}$} & \multicolumn{2}{|c|}{$\begin{array}{l}\text { Coordination } \\
\text { Costs per } \\
\text { Interaction } \\
\text { for } \\
\text { Implementing } \\
\text { Innovations }\end{array}$} & \multicolumn{2}{|c|}{$\begin{array}{l}\text { Critical Mass } \\
\text { for } \\
\text { Implementing } \\
\text { Innovations }\end{array}$} \\
\hline & & & Min. & Max. & Min. & Max. & Min. & Max. & Min. & Max. & Min. & Max. \\
\hline Polyarchy & 1000 & 500 & -20 & 20 & 0 & 20 & n.a. & n.a. & n.a. & n.a. & n.a. & n.a. \\
\hline Hierarchy (1 Level Hierarchy) & 1000 & 500 & -20 & 20 & 0 & 20 & 0.5 & 1 & n.a. & n.a. & n.a. & n.a. \\
\hline Hierarchy (2 Level Hierarchy) & 1000 & 500 & -20 & 20 & 0 & 20 & 0.5 & 1 & n.a. & n.a. & n.a. & n.a. \\
\hline Hierarchy (3 Level Hierarchy) & 1000 & 500 & -20 & 20 & 0 & 20 & 0.5 & 1 & n.a. & n.a. & n.a. & n.a. \\
\hline
\end{tabular}

\begin{tabular}{|c|c|c|c|c|c|c|c|c|c|c|c|c|}
\hline \multirow[t]{2}{*}{$\begin{array}{l}\text { Innovations with Spillover } \\
\text { Effects }\end{array}$} & \multirow[t]{2}{*}{$\begin{array}{l}\text { Number of } \\
\text { Organizations }\end{array}$} & \multirow[t]{2}{*}{$\begin{array}{l}\text { Number of } \\
\text { Employees } \\
\text { per Org. }\end{array}$} & \multicolumn{2}{|c|}{$\begin{array}{l}\text { Mean of the } \\
\text { Employees' } \\
\text { Innovations } \\
\text { per } \\
\text { Organization }\end{array}$} & \multicolumn{2}{|c|}{$\begin{array}{l}\text { Standard } \\
\text { Deviation of } \\
\text { the } \\
\text { Employees' } \\
\text { Innovation }\end{array}$} & \multicolumn{2}{|c|}{$\begin{array}{l}\text { Quality of } \\
\text { Decision for } \\
\text { Assessing } \\
\text { Innovations }\end{array}$} & \multicolumn{2}{|c|}{$\begin{array}{l}\text { Coordination } \\
\text { Costs per } \\
\text { Interaction } \\
\text { for } \\
\text { Implementing } \\
\text { Innovations }\end{array}$} & \multicolumn{2}{|c|}{$\begin{array}{l}\text { Critical Mass } \\
\text { for } \\
\text { Implementing } \\
\text { Innovations }\end{array}$} \\
\hline & & & Min. & Max. & Min. & Max. & Min. & Max. & Min. & Max. & Min. & Max. \\
\hline Polyarchy & 1000 & 500 & -20 & 20 & 0 & 20 & n.a. & n.a. & 0 & 10 & n.a. & n.a. \\
\hline Polyarchy (with Assessment) & 1000 & 500 & -20 & 20 & 0 & 20 & 0.5 & 1 & 0 & 10 & n.a. & n.a. \\
\hline Hierarchy (1 Level Hierarchy) & 1000 & 500 & -20 & 20 & 0 & 20 & 0.5 & 1 & 0 & 10 & n.a. & n.a. \\
\hline Hierarchy (2 Level Hierarchy) & 1000 & 500 & -20 & 20 & 0 & 20 & 0.5 & 1 & 0 & 10 & n.a. & n.a. \\
\hline Hierarchy (3 Level Hierarchy) & 1000 & 500 & -20 & 20 & 0 & 20 & 0.5 & 1 & 0 & 10 & n.a. & n.a. \\
\hline Hybrid (1 Level Hierarchy) & 1000 & 500 & -20 & 20 & 0 & 20 & 0.5 & 1 & 0 & 10 & n.a. & n.a. \\
\hline Hybrid (2 Level Hierarchy) & 1000 & 500 & -20 & 20 & 0 & 20 & 0.5 & 1 & 0 & 10 & n.a. & n.a. \\
\hline Hybrid (3 Level Hierarchy) & 1000 & 500 & -20 & 20 & 0 & 20 & 0.5 & 1 & 0 & 10 & n.a. & n.a. \\
\hline
\end{tabular}

\begin{tabular}{|c|c|c|c|c|c|c|c|c|c|c|c|c|}
\hline \multirow[t]{2}{*}{$\begin{array}{l}\text { Innovations that Require a } \\
\text { Critical Mass }\end{array}$} & \multirow[t]{2}{*}{$\begin{array}{l}\text { Number of } \\
\text { Organizations }\end{array}$} & \multirow[t]{2}{*}{$\begin{array}{l}\text { Number of } \\
\text { Employees } \\
\text { per Org. }\end{array}$} & \multicolumn{2}{|c|}{$\begin{array}{l}\text { Mean of the } \\
\text { Employees' } \\
\text { Innovations } \\
\text { per } \\
\text { Organization }\end{array}$} & \multicolumn{2}{|c|}{$\begin{array}{l}\text { Standard } \\
\text { Deviation of } \\
\text { the } \\
\text { Employees' } \\
\text { Innovation }\end{array}$} & \multicolumn{2}{|c|}{$\begin{array}{l}\text { Quality of } \\
\text { Decision for } \\
\text { Assessing } \\
\text { Innovations }\end{array}$} & \multicolumn{2}{|c|}{$\begin{array}{l}\text { Coordination } \\
\text { Costs per } \\
\text { Interaction } \\
\text { for } \\
\text { Implementing } \\
\text { Innovations }\end{array}$} & \multicolumn{2}{|c|}{$\begin{array}{l}\text { Critical Mass } \\
\text { for } \\
\text { Implementing } \\
\text { Innovations }\end{array}$} \\
\hline & & & Min. & Max. & Min. & Max. & Min. & Max. & Min. & Max. & Min. & Max. \\
\hline Polyarchy & 1000 & 500 & -1000 & 1000 & 0 & 1000 & n.a. & n.a. & 0 & 10 & 0 & 1 \\
\hline Polyarchy (with Assessment) & 1000 & 500 & -1000 & 1000 & 0 & 1000 & 0.5 & 1 & 0 & 10 & 0 & 1 \\
\hline Hierarchy (1 Level Hierarchy) & 1000 & 500 & -1000 & 1000 & 0 & 1000 & 0.5 & 1 & 0 & 10 & 0 & 1 \\
\hline Hierarchy (2 Level Hierarchy) & 1000 & 500 & -1000 & 1000 & 0 & 1000 & 0.5 & 1 & 0 & 10 & 0 & 1 \\
\hline Hierarchy (3 Level Hierarchy) & 1000 & 500 & -1000 & 1000 & 0 & 1000 & 0.5 & 1 & 0 & 10 & 0 & 1 \\
\hline Hybrid (1 Level Hierarchy) & 1000 & 500 & -1000 & 1000 & 0 & 1000 & 0.5 & 1 & 0 & 10 & 0 & 1 \\
\hline Hybrid (2 Level Hierarchy) & 1000 & 500 & -1000 & 1000 & 0 & 1000 & 0.5 & 1 & 0 & 10 & 0 & 1 \\
\hline Hybrid (3 Level Hierarchy) & 1000 & 500 & -1000 & 1000 & 0 & 1000 & 0.5 & 1 & 0 & 10 & 0 & 1 \\
\hline
\end{tabular}

Source: Own Table

Each simulation was run with 1000 iterations and 500 agents per organization for each of the 20 models investigated. To look at the effect of age and size of organizations we initially modeled each specification at organization size 25, 50, 100, 250 and 500 agents, and noted that the findings were similar except that the 500 ones, having more points, gave a more precise analysis of the findings. In the simulations shown, the decisive differences between projects with incremental effects and projects that require a critical mass are the mean and the standard deviations of individuals' innovations. In the case of incremental projects, the mean cash value of the project differs between -20 and +20 monetary units 
(MU), while the standard deviation can go up to 20. For projects with a critical mass, organizations might reach much higher (absolute) cash values if they manage to implement such innovations and therefore we use a mean cash value between $-1,000$ and 1,000 MU with a standard deviation of up to 1,000 for such projects.

As seen previously, projects with spillover effects and projects that require a critical mass entail coordination costs. In these simulations the coordination costs were set between 0 and $10 \mathrm{MU}$ across organizations and are constant within each organization. The reason for this was because when coordination costs add up to $10 \mathrm{MU}$ in the extreme example, only three people could implement an incremental project with a cash value of $20 \mathrm{MU}$ : the initiator (net value $=20 \mathrm{MU}$ because of no coordination costs) and two change aides (where the net value for these two in sum = $10 \mathrm{MU}$ because of gains of $40 \mathrm{MU}$ and coordination costs of $30 \mathrm{MU})$. In the case of a project requiring a critical mass with a cash value of 1,000 MU, the critical mass must be below $20 \%$ because otherwise project initiators will never reach the critical mass needed. If the critical mass exceeded $20 \%$ then the high coordination costs would prevent the adoption of the project through the organization. Lastly; in the case of a polyarchy with change aide assessment, the critical mass needs to be much lower just because of the statistical occurrence of type one errors.

\section{Findings: How Organizational Structure Transforms Initial Projects into Performance}

Table 2 shows the empirical results of our simulations by summarizing (1) the average profit for an organization (see first row), the standard deviation of the profits (e.g. the risk, see second row) and (2) adds the slopes of the explanatory parameters that were used for estimating organizational performance. Two model types were used: The first type (see third row) is a univariate OLS regression of the organization's mean value of an innovation on organizational performance (e.g. the sum of all cash values of all implemented good and bad innovations). The second type of OLS regressions estimate the organizational performance as a linear function of the parameters organization's mean value of an innovation, quality of decision, coordination costs and critical mass (rows four to seven). The slopes of our regressions describe to what extent changes in the underlying parameters influence corporate performance.

(1) Average organization's profit and risk: All simulations showed that additional hierarchical levels increase the average profitability in those cases where innovations have spillover effects or require a 
critical mass by reducing the collective risk of the organization (see column standard deviation in Table 2). Additional hierarchical levels showed a reduced marginal effect on profitability and risk: implementing a hierarchy with one-level in a polyarchical organization has a much stronger effect than increasing the hierarchical levels from two to three. This effect can be seen by considering the slope of the innovation's mean where the OLS estimated parameter (see rows three and four) can be interpreted as the average aggregation of innovations into organizational performance: What would be the aggregated effect if we could increase the mean of the initial project portfolio by 1 Monetary Unit for all 500 agents in the organization (for example through employee training that increases the organization's mean of the average innovation)? As the numbers highlight, additional hierarchical levels reduce this slope (for example for a hierarchy incremental effects as shown in the third column "Regression Model I": a slope of 248 for a one-level hierarchy, 166 for a two-level, and 125 for a three-level hierarchy) because of the structure’s influence on omission and commission errors (Sah \& Stiglitz, 1985 and 1986, see also Csaszar, 2012). As a consequence, more hierarchical levels systematically increase the number of rejected projects, the immediate consequences of which include that the collective risk (see second row) is reduced and this holds for all project types and organizations.

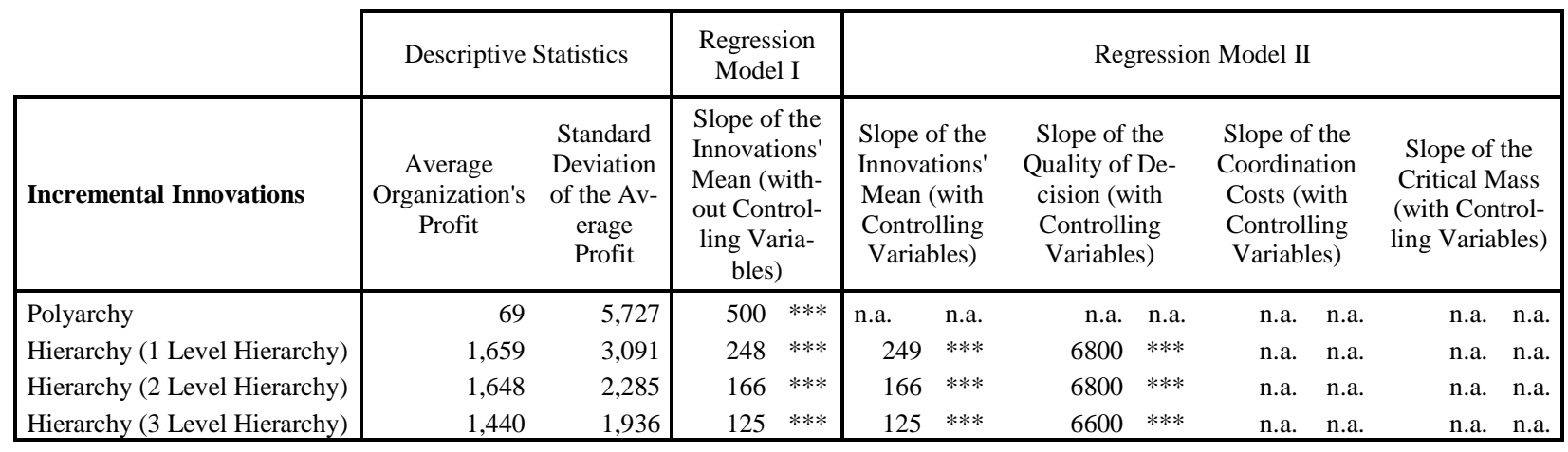

\begin{tabular}{|c|c|c|c|c|c|c|c|c|c|c|c|}
\hline \multirow{3}{*}{$\begin{array}{l}\text { Innovations with Spillover } \\
\text { Effects } \\
\text { Polyarchy }\end{array}$} & \multicolumn{2}{|c|}{ Descriptive Statistics } & \multirow{2}{*}{\multicolumn{2}{|c|}{$\begin{array}{c}\begin{array}{c}\text { Regression } \\
\text { Model I }\end{array} \\
\text { Slope of the } \\
\text { Innovations' } \\
\text { Mean (with- } \\
\text { out Control- } \\
\text { ling Varia- } \\
\text { bles) }\end{array}$}} & \multicolumn{7}{|c|}{ Regression Model II } \\
\hline & \multirow{2}{*}{\begin{tabular}{|c}
$\begin{array}{c}\text { Average } \\
\text { Organization's } \\
\text { Profit }\end{array}$ \\
$-169,680$
\end{tabular}} & \multirow[t]{2}{*}{$\begin{array}{c}\begin{array}{c}\text { Standard } \\
\text { Deviation } \\
\text { of the Av- } \\
\text { erage } \\
\text { Profit }\end{array} \\
4,489,632\end{array}$} & & & \multicolumn{2}{|c|}{$\begin{array}{l}\text { Slope of the } \\
\text { Innovations' } \\
\text { Mean (with } \\
\text { Controlling } \\
\text { Variables) }\end{array}$} & \multicolumn{2}{|c|}{$\begin{array}{l}\text { Slope of the } \\
\text { Quality of De- } \\
\text { cision (with } \\
\text { Controlling } \\
\text { Variables) }\end{array}$} & \multicolumn{2}{|c|}{$\begin{array}{l}\text { Slope of the } \\
\text { Coordination } \\
\text { Costs (with } \\
\text { Controlling } \\
\text { Variables) }\end{array}$} & $\begin{array}{l}\text { Slope of the } \\
\text { Critical Mass } \\
\text { (with Control- } \\
\text { ling Variables) }\end{array}$ \\
\hline & & & 22000 & * & n.a. & n.a. & n.a. & n.a. & n.a. & n.a. & n.a. n.a. \\
\hline Polyarchy (with Assessment) & $-5,505$ & 576,010 & 5500 & $* * *$ & 5600 & $* * *$ & -12000 & & 5300 & & n.a. n.a. \\
\hline Hierarchy (1 LevelHierarchy) & $-5,511$ & 577,154 & 5500 & $* * *$ & 5600 & $* * *$ & -12000 & & 5300 & & n.a. n.a. \\
\hline Hierarchy (2 Level Hierarchy) & 14,615 & 195,746 & 2700 & $* * *$ & 2500 & $* * *$ & 74000 & * & -5400 & *** & n.a. n.a. \\
\hline Hierarchy (3 Level Hierarchy) & 15,831 & 155,914 & 1800 & $* * *$ & 1700 & $* * *$ & 78000 & $* *$ & -6200 & $* * *$ & n.a. n.a. \\
\hline Hybrid (1 LevelHierarchy) & $-30,017$ & $1,170,256$ & 8800 & $* * *$ & 9200 & $* * *$ & -130000 & & 18000 & & n.a. n.a. \\
\hline Hybrid (2 Level Hierarchy) & $-7,876$ & 676,657 & 6500 & $* * *$ & 6600 & $* * *$ & -23000 & & 6700 & & n.a. n.a. \\
\hline
\end{tabular}




\begin{tabular}{|c|c|c|c|c|c|c|c|c|c|c|c|c|}
\hline \multirow[t]{2}{*}{ Hybrid (3 Level Hierarchy) } & $-4,408$ & 608,932 & 6000 & $* * *$ & 6100 & $* * *$ & -13000 & \multicolumn{3}{|c|}{4900} & n.a. & n.a. \\
\hline & \multicolumn{2}{|c|}{ Descriptive Statistics } & \multicolumn{2}{|c|}{$\begin{array}{l}\text { Regression } \\
\text { Model I }\end{array}$} & \multicolumn{8}{|c|}{ Regression Model II } \\
\hline $\begin{array}{l}\text { Innovations Requiring a } \\
\text { Critical Mass }\end{array}$ & $\begin{array}{c}\text { Average } \\
\text { Organization's } \\
\text { Profit }\end{array}$ & $\begin{array}{c}\text { Standard } \\
\text { Deviation } \\
\text { of the Av- } \\
\text { erage } \\
\text { Profit }\end{array}$ & \multicolumn{2}{|c|}{$\begin{array}{l}\text { Slope of the } \\
\text { Innovations' } \\
\text { Mean (with- } \\
\text { out Control- } \\
\text { ling Varia- } \\
\text { bles) }\end{array}$} & \multicolumn{2}{|c|}{$\begin{array}{l}\text { Slope of the } \\
\text { Innovations' } \\
\text { Mean (with } \\
\text { Controlling } \\
\text { Variables) }\end{array}$} & \multicolumn{2}{|c|}{$\begin{array}{l}\text { Slope of the } \\
\text { Quality of De- } \\
\text { cision (with } \\
\text { Controlling } \\
\text { Variables) }\end{array}$} & \multicolumn{2}{|c|}{$\begin{array}{l}\text { Slope of the } \\
\text { Coordination } \\
\text { Costs (with } \\
\text { Controlling } \\
\text { Variables) }\end{array}$} & \multicolumn{2}{|c|}{$\begin{array}{l}\text { Slope of the } \\
\text { Critical Mass } \\
\text { (with Control- } \\
\text { ling Variables) }\end{array}$} \\
\hline Polyarchy & $-70,769$ & 209,992 & 122 & $* * *$ & n.a. & n.a. & n.a. & n.a. & n.a. & n.a. & n.a. & n.a. \\
\hline Polyarchy (with Assessment) & $-6,396$ & 143,818 & 136 & $* * *$ & 139 & $* * *$ & 210,000 & $* * *$ & 3,000 & $* *$ & 31,000 & $* *$ \\
\hline Hierarchy (1 Level Hierarchy) & 4,890 & 90,412 & 105 & $* * *$ & 107 & $* * *$ & 170,000 & $* * *$ & $-2,600$ & $* * *$ & $-38,000$ & $* * *$ \\
\hline Hierarchy (2 Level Hierarchy) & 16,173 & 61,046 & 60 & $* * *$ & 61 & $* * *$ & 130,000 & $* * *$ & $-3,900$ & $* * *$ & $-49,000$ & $* * *$ \\
\hline Hierarchy (3 Level Hierarchy) & 16,716 & 48,902 & 40 & $* * *$ & 41 & $* * *$ & 110,000 & $* * *$ & $-3,700$ & $* * *$ & $-46,000$ & $* * *$ \\
\hline Hybrid (1 LevelHierarchy) & $-15,441$ & 152,307 & 170 & $* * *$ & 174 & $* * *$ & 220,000 & $* * *$ & 3,300 & $* * *$ & 27,000 & $* *$ \\
\hline Hybrid (2 Level Hierarchy) & $-6,986$ & 147,177 & 150 & $* * *$ & 153 & $* * *$ & 220,000 & $* * *$ & 2,800 & $* *$ & 27,000 & $* *$ \\
\hline Hybrid (3 Level Hierarchy) & $-5,341$ & 145,667 & 143 & $* * *$ & 146 & $* * *$ & 210,000 & $* * *$ & 2,800 & $* *$ & 27,000 & $* *$ \\
\hline
\end{tabular}

Table 2: An overview of the empirical findings. Note: The stars indicate the following significance levels: $*<0.1, * *<0.05$ and $* * *<0.01$. Own calculations.

Regarding the interdependence of the number of hierarchical levels with profitability (see Table 2, first row), the mixed results obtained illustrate that profitability can depend on the interactions between the characteristics of the portfolio of the initial projects and the organizational structures. Firstly, the number of hierarchical levels has a reversed U-shape effect on profitability in the case of innovations with incremental effects. Thus, there is a tradeoff between increasing profitability and reducing risks. The other two initial portfolios show only a declining effect. The reason for this is that innovations with spillover effects, as well as those that require a critical mass, cause a distribution function, which in turn is more extreme and skewed to the left and this is because communication costs and collective myopia (in the case of errors of the second order) reinforce each other. In this situation, additional hierarchical levels have a positive net effect: on the one side, the firm has to abandon any positive effects of myopia because of errors of the first order; however, the net effect of rejected 'bad' innovations is stronger. In these simulations the reversed U-shape effect of hierarchical levels on profitability appears absent, although this effect could possibly emerge if the simulations were run again with 4 or more levels of hierarchy. Another finding is that multi-level hierarchies achieve a high number of rejected projects and are thus quite robust against the negative effects of joint myopia. Even multi-hierarchical organizations with a poor assessment of innovations achieve relatively good results compared to polyarchies or hybrid organizations. Thus, in a world in which employees tend to think up 'bad' innovations, employing a hierarchy of poor managers is still much better than having no hierarchy at all or having hybrid architectures. 
Indeed, when we insert extreme values, we see that hierarchies can achieve better results even where the decision-making ability of the management only marginally exceeds coin-flipping frequency. These results support the findings of Ethiraj \& Levinthal (2004b) as well as Siggelkow \& Rivkin (2005), who argue that concentration into highly centralized firms may be the superior alternative when the environment is complex and turbulent, whatever the quality of managers' decision-making is.

(2) The explanatory role of the innovations' mean cash value, assessment quality, and coordination costs on organizational performance: The quality of decision making (see Table 2, fifth row) is reminiscent of what Siggelkow \& Rivkin (2005, p. 119) described as “interdependencies can create surprising and subtle effects that, without systematic analysis, can lead intuition astray." In the case of an initial project portfolio with incremental innovations, the quality of managerial decision making has a similar effect on organizational performance independent of the levels of hierarchy (as the first row of Table 2 highlights). In the case of innovations with spillover effects in a hierarchy, the corresponding slope for managerial quality is much steeper than for innovations with only incremental effects. In a hierarchy, one sees the strongest effect of managerial quality in the case of innovations that require overcoming a critical mass, because the quality of the managers decision-making has enormous consequences for the organization: in the case of rejecting a good innovation, opportunity costs are quite high, and in the case of accepting a bad innovation, the losses may become enormous. In addition to this, the slope of managerial quality in hierarchies declines when the number of hierarchies is increased because managers have a much stronger effect on corporate performance in flatter organization. But this only holds for innovations that have to overcome a critical mass.

Concerning polyarchies and hybrid organizations regarding innovations with spillover effects, the quality of the assessment does not seem to have any straightforward effect, in that the estimated parameters have a negative sign but are not statistically significant. This may be related to the results of Knudsen and Srikanth (2014) who reported from their simulations that polyarchies and hybrid organizations might be over-challenged when undergoing coordinated exploration and because of this, the decision quality of individual agents in these organizations cannot systematically influence the overall collective performance. 
Coordination costs and the size of the critical mass hurdle (Table 2, see rows six and seven) have quite different effects on organizational performance depending on the organizational architecture. Firstly, hierarchical organizations become much more profitable when they achieve a reduction of coordination costs and/or critical mass, because it is easier for innovators and their superiors to exceed lower critical mass hurdles, in order to implement innovations and the same is seen for coordination costs. Secondly, for polyarchies and hybrid organizations the situation is exactly reversed regarding the influence of coordination costs and the critical mass. Higher coordination costs and a higher critical mass increase the performance. The reason for this surprising and counter-intuitive result is that agents can also initiate bad innovations and under these conditions, incurring high coordination costs and/or a high critical mass hurdle prevents poor innovations from spreading and this reduces potential losses. Shortly, for polyarchies and hybrid organizations it is better to relinquish good projects because of a high organizational inertia, rather than implementing more projects that have high risks in terms of performance. This finding supports the argument of Nickerson \& Zenger (2003) that inertia does not necessarily have to have negative consequences for the organization.

In the case of innovations that have to overcome a critical mass, the gradients of the slopes measuring the impact of innovations' cash values on performance are much higher for hybrid organizations than for hierarchies and even higher than the corresponding slopes derived for polyarchies, which shows that improving the initial project portfolio has a much higher impact on a hybrid organization than in any other organizational structure. For example, for innovations that require a critical mass the slopes in the third and fourth row of Table 2 show that a hybrid organization has 3.5 times higher "leverage" of transforming innovations into corporate performance compared to an organization with three hierarchical levels). Comparing hierarchies with hybrids in the case of innovations with spillover effects, similar values are seen and indeed slopes are greater than the slopes pertaining to firms with just one hierarchical level but adding more hierarchical levels in hybrid organizations only caused a slight reduction in the steep slope, including with projects that require a critical mass.

The results reported here support the idea of Csaszar (2013), namely that exploration and exploitation are not achieved through different processes, but rather they are the aggregated consequences of the 
same (micro) processes within different architectures. We show that polyarchies and hybrid organizations are much more explorative than hierarchies for projects with spillover effects and those that require a critical mass, nevertheless hierarchies achieve in average a higher performance and can reduce the risks of initial project portfolios through selecting out more (explorative) projects. From this point of view, hierarchies promote exploitation, and this might even give them a competitive advantage as long as explorative projects involved are quite risky. Obviously, a higher quality of managerial decisionmaking within a hierarchy will tend to increase exploration because managers will make fewer errors of the first order. However, the low gradients of the slopes of the innovations' effects reveal that even here, the architecture may retain dominance for hierarchies, when compared to polyarchies and hybrid organizations.

\section{Discussion}

\subsection{From optimizing within structures to designing organizational architectures:}

Summarizing our findings in the light of previous reports, our simulations largely confirm the overall findings of Sah \& Stiglitz $(1985,1986)$ and Csaszar (2012) in that decentralized structures seem to accept more innovations because of fewer errors of the first order (e.g. commission errors) and more errors of the second order (e.g. omission errors). Additionally, our findings also confirm the result of Knudson \& Levinthal (2007) that the average performance of hybrid structures lies between the performance of hierarchies and polyarchies. Our findings also echo Siggelkow \& Rivkin (2005) and Csaszar \& Eggers (2013), who argue that adaptations of the organizational architecture may cause surprising performance effects, and this confirmation may provoke further analyses on the variance and risk that is leveraged by the organizational structure (see Csaszar \& Eggers, 2013). 


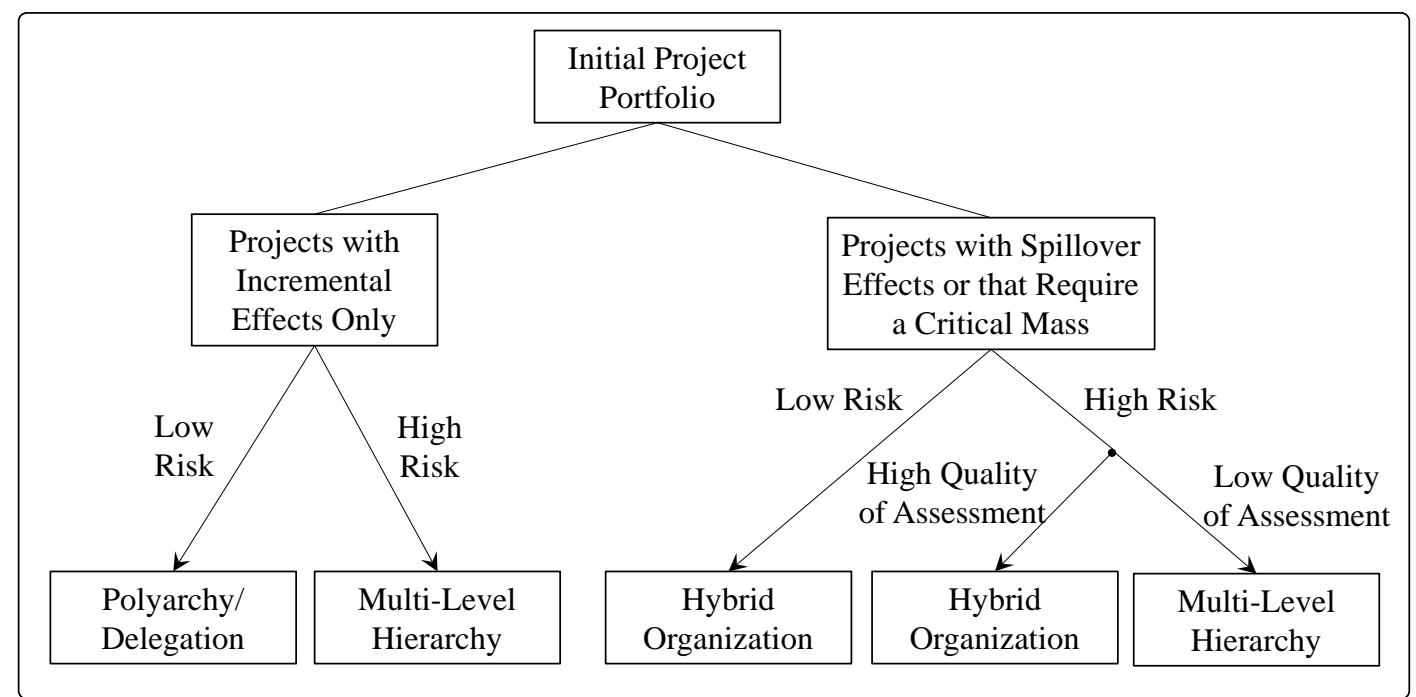

Figure 8: Designing an organization (own figure)

Hitherto unreported findings included in this work are firstly that systematic dependencies exist between project selection on the individual level, organizational structures and corporate performance, indicating that the aggregation of agents' decisions is not as chaotic as other scholars have assumed (see e.g. Abell et al., 2008; and also Barney \& Felin, 2013; Felin et al., 2015; Goldstein, 1999; Sawyer, 2002) but rather, that subtle interdependencies exist. Christensen \& Knudsen (2010, p. 84) argue that most contributions in the field of management research focus on optimizing organizations, however finding an appropriate organizational design would appear to be a fundamental challenge that has to be answered before one can turn to optimizing already existing architectures. Figure 8 summarizes how different parameters may define which organizational architecture is superior.

\subsection{The Superiority of Hybrid Organizations:}

Figure 8 summarizes that a strict multi-level hierarchy is superior compared to all other architectures in environments where initial innovation portfolios are on average poor, or contain a high risk of failing (e. g. many bad and good innovations, see Khanna et al., 2016; Perry-Smith \& Mannucci, in press) and where it is quite difficult to assess the quality of projects, indeed even in hierarchies where the quality of managers' assessment is poor to the point of random choice, they may still be the best route. The regression results highlight (see the slopes in row three and four of Table 2) that where the initial portfolio is quite risky but where agents are aware and able to evaluate the quality of projects, then hybrids 
might be a superior form of organization because the horizontal and vertical communication pathways within hybrids enable them to have alternatives for spreading good innovations in the case of managerial omission errors. Nevertheless in the case of risky innovations portfolios, hybrid organizations are also vulnerable, being liable to joint myopia. Because of this, introducing even a low probability of committing commission errors may cause adverse effects.

Regarding initial portfolios containing low-risk projects, the performance of hierarchies was inferior compared to polyarchies and hybrid organizations. The reason for this is that hierarchies systematically reject more innovations (see also Sah \& Stiglitz, 1985, 1986 as well as Csaszar, 2012) and indeed the gradients of the slopes that illustrate the aggregation of initial portfolios are much steeper in polyarchies and hybrid organizations (see the slopes in row three and four of Table 2). Depending on the initial portfolio, polyarchies are superior in the case of innovations with spillover effects which are not assessed by the agents, whereas hybrid architectures are superior in the case of innovations that require a critical mass or when agents assess projects that may cause spillover effects. In the former case, herd behavior causes high gains in a polyarchy because of the low risks associated with the innovation and because of the absence of hierarchical structures that might intervene and cause commission errors. In the latter case, hybrid structures are superior because the concatenation of horizontal and hierarchical structures enables agents to initiate projects even when commission errors happen.

\subsection{The Superiority of Polyarchies:}

That polyarchies achieve poor results in average and reach only a good performance if the initial innovation portfolio has low risks, fits well in the research on market failure (e.g. market for lemons, see Akerlof, 1970, Kultti et al., 2012, Moreno \& Wooders, 2016): Markets (that are polyarchy-like structures) may collapse because actors have issues in assessing the real risks of an interaction, and indeed markets work quite well if interactions are low-risk. Even if we perceive polyarchic markets as daily and wide-spread phenomena, the interactions that take place there are highly restrained regarding risk.

\subsection{Improving the Performance of Hierarchies:}


While analyzing which structures might be superior in a given context, in many cases finding an appropriate organizational design would appear a prerequisite before one can turn to optimizing already existing architectures, and thus it appears essential to determine how existing organizations might be adapted to become more successful. This question of re-designing organizations is especially addressed in the literature on the ambidextrous organization (Benner \& Tushman, 2003; Benner \& Tushman, 2015; and O’Reilly III \& Tushman, 2013) and as Csaszar (2012) points out; ambidexterity does not emerge through different processes within an organization, but is rather a consequence of the organization's architecture. If that is the case, then the findings reported here may well be relevant to the question of how to make hierarchical organizations more ambidextrous. Table 2 and Figure 8 show that when the initial projects have a low risk of failure, the hierarchical organization benefits most when decisions are made on low hierarchical levels or if horizontal structures are added to the hierarchy for creating a more hybrid organization, and indeed the introduction of a more hybrid structure might be superior compared to delegation to lower hierarchical levels.

However, if initial innovations are risky, then hierarchies are more resilient than polyarchic organizations and, under conditions of high risks, organizations can follow two different approaches as to how to handle these risks; either by adding further hierarchical instances on decision-making, or by increasing the quality of the decision-making process. Of course, hybrid organizations can also benefit by increasing the quality of decision-making but in a hybrid organization the decision-making quality has to be increased throughout the whole organization, while in hierarchies the decision-making quality is localized to the hierarchy and needs only to be increased in the management layer, a cheaper and easier option.

Of course, another option might be to seek advice outside the organization, using experts or special structures (Knudsen \& Srikanth, 2014, pp. 432-433) that select innovations from portfolios regarding potential risks. This would mean that innovations with low risks can be decided upon by low hierarchical levels or within hybrid structures, while risky innovations have to be decided through multi-level hierarchies. This raises the prospect that the open innovation literature (Cheng et al., 2014; Felin \& Zenger, 2014, Benner \& Tushman, 2015, West \& Bogers, 2013, Wolter \& Veloso, 2008) and most parts of the research on ambidexterity (Benner \& Tushman 2003, Benner \& Tushman 2015; and O’Reilly III \& 
Tushman, 2013) might be biased regarding the handling of risky innovations through architectures other than the traditional hierarchy. From an ex-post perspective, it is easy to say that a reduction in the hierarchy and the removal of clear boundaries may promote exploration, and this can lead to great innovations; but the prerequisite is that the number of commission errors must be low even when the environment is risky. Our findings reveal that as long as hierarchical firms cannot reduce the number of commission errors in a risky environment, then a multi-level hierarchy is superior, even when it entails rejecting some great innovations.

The results presented here are also relevant regarding the role of team structures in explaining corporate performance. Scholars like Chen et al. (2013); Foss \& Lindenberg (2012; 2013); Harvey (2014); Lindenberg \& Foss (2011); Reagans et al. (2016) and Young-Hyman (2016) have argued that firms with team structures are more beneficial than hierarchical firms with a strict vertical communication, but the results presented here show that erecting team structures causes a more hybrid organization, which in turn is an extremely risky gambit if the organization exists in an environment with a large proportion of innovations that are unsuitable for the firm. Such team structures may promote negative forms of collective myopia and reduce the resilience against "bad" innovations that require a critical mass. In other words, something like Google’s often-praised organizational structure (see Yarow, 2015) might only be "best practice" when employees come up with positive projects and exhibit a high degree of expert decision making when evaluating innovations proposed by their colleagues. Otherwise replicating Google’s organizational structure may well cause high deficits.

\subsection{Hierarchies, polyarchies and the theory of the firm:}

Interestingly our findings contain a strong supplement to the "theory of the firm” (Coase, 1937), which explains the existence of the hierarchical firm through the relatively high transaction costs for market interactions. Our results strongly imply that in parallel to transaction costs, another logic may sustain the existence of hierarchical firms, namely reducing the risk of choosing poor projects, which in turn implies that introducing new technologies that reduce transaction costs do not necessarily have to result in the collapse of the traditional hierarchical firm. As Miller (1992) highlights, the hierarchical firm with clear formal boundaries was a consequence of the industrialized mass production process with assembly 
lines, and thus reduced transaction costs and new forms of value creation processes may allow a return to pre-assembly line structures: it would become easier for freelancers, small organizations and also big firms to cooperate (see e.g. Benner \& Tushman, 2015; p. 507; Cheng et al., 2014; Felin \& Zenger, 2014; West \& Bogers, 2013 as well as Wolter \& Veloso, 2008). However, in a world with low transaction costs and risky innovations, firms may emerge with a formal core surrounded by an open structure of horizontal teams and networks with open boundaries for provoking, spreading and harvesting innovations, while the formal core contains an efficient hierarchy for selecting only appropriate projects. Indeed, this also applies to non-profit organizations (NPOs). Firstly, NPOs also have to choose projects for achieving their social and ecological agendas. These projects might also be risky and as a consequence, hierarchies might be necessary even if these organizations often perceive themselves as being quite different compared to well-established for-profit firms (Valentinov et al. 2015, Will 2015, Will et al. 2017b). Our findings also explain why many big players in the NPO sector (e.g. Greenpeace or Oxfam) have multi-level hierarchies for selecting their projects on the one side and on the other side polyarchical networks of supporters for fund-raising and communicating the organization's agendas. In the light of our findings, this is hardly surprising because fund-raising and communicating agendas that are already decided upon, is low-risk compared to selecting an NPO's project. Secondly, this and previous work (Csaszar \& Eggers, 2013) shows that the democratization of the firm (Hielscher et al., 2014) may cause enormous challenges in actually selecting projects and implementing innovations. Thus, it is hardly surprising that some researchers e.g. Michelsen (1994) and Schneiberg (2011) found only few examples of successful cooperation between similar polyarchies in competitive market economies, and the findings presented here can now actually explain this well-known effect, namely that such structures promote joint myopia and this in turn threatens the organization.

\section{Concluding Remarks and Further Research}

Scholars from the field of organizational behavior including Chen et al. (2013); De Dreu \& West (2001); Foss \& Lindenberg (2012); Harvey (2014); Hewlett et al. (2013) as well as Lovelace et al. (2001) all argue that "hybrid" team structures may increase idea generation, innovative behavior and, finally, cor- 
porate performance. Thus, teams are regarded as better for transforming ideas into productive innovations. This behavioral approach has strong arguments giving rise to serious doubts around the question if rigid hierarchies can be competitive in the long run. The results presented here are based on the reality that poor projects can also spread throughout the organization, resulting in high losses, and that this is especially damaging when peers have difficulties in assessing the quality of the project to be introduced. Our findings indicate that hybrid organizations with hierarchies and horizontal team-structures might be highly competitive as long as agents' decision quality is high or as the projects’ risks are low. Secondly, organizations can also become more hybrid by deciding which projects can be decided in a hybrid structure and which projects have to be decided within a clear hierarchy. Further research might use these findings and add behavioral feedback effects on motivation and project selection that might emerge through hybrid structures (Alexander \& van Knippenberg, 2014; Hodgkinson \& Healey, 2014; Lindenberg, 2015; as well as Powell et al., 2011, pp. 1374-1376).

March (1991) as well as Vargas-Hernández (2011) highlighted that risk- and innovation management may be complementary, and this study supports their view insomuch as this relationship follows from interdependencies between organizational architecture, performance and risk. As we highlight, an appropriate organizational design may increase profits and reduce risks through a clever selection of projects until a given point is reached at which a tradeoff between profitability and risk emerges. Beyond this point, additional profits are only possible with increased chance of additional risk. Our argumentation (summarized in Figure 8) gives some ideas of how organizations can move this point. Nevertheless, a specific organizational context may require highly pronounced structures for avoiding tradeoffs between risks and profits. Finding such solutions is an empirical challenge and further empirical research on firm parameters (size, organizational structure, staff's qualifications, investments in R\&D, etc.) is needed as well as contemplating more global industry indicators (degree of competition, proximity to a cluster, embeddedness into global value chains, etc.) before this can be resolved.

\section{Acknowledgements}

We acknowledge colleagues (at several conferences and otherwise) whose discussions and feedback have helped shape and develop this work. 


\section{References}

Abell, Peter, Teppo Felin, and Nicolai Foss (2008): Building Micro-Foundations for the Routines, Capabilities, and Performance Links, in: Managerial and Decision Economics, Vol. 29, pp. 489502.

Acs, Zoltan J., Pontus Braunerhjelm, David B. Audretsch and Bo Carlsson (2009): The knowledge spillover theory of entrepreneurship, in: Small Business Economics, Vol. 32, No. 1, pp. 15-30.

Akerlof, George A. (1970): The Market for Lemons: Quality Uncertainty and the Market Mechanism, in: Quarterly Journal of Economics, Vol. 84, No. 3, pp. 488-500.

Alexander, Lameez, and Daan Van Knippenberg (2014): Teams in Pursuit of Radical Innovation: A Goal Orientation Perspective, in: Academy of Management Review, Vol. 39, No. 4, pp. 423-438.

Almirall, Esteve, and Ramon Cadadesus-Masanell (2010): Open Versus Closed Innovation: A Model of Discovery and Divergence, in: Academy of Management Review, Vol. 35, No. 1, pp. 27-47.

Argyres, Nicholas S. and Brian S. Silverman (2004): R\&D, Organization Structure, and the Development of Corporate Technological Knowledge, in: Strategic Management Journal, Vol. 25, pp. 929-958.

Baregheh, Anahita. Rowley, Jennifer and Sambrook, Sally. (2009): Towards a multidisciplinary definition of innovation. Management Decision, Vol. 47 Issue: 8, pp 1323-1339.

Barney, Jay, and Teppo Felin (2013): What are Microfoundations, in: The Academy of Management Perspectives, Vol. 27, No. 2, pp. 138-155.

Benner, Mary J., and Michael L. Tushman (2003): Exploitation, Exploration, and Process Management: The Productivity Dilemma Revisited, in: Academy of Management Review, Vol. 28, No. 2, pp. 238-256.

Benner, Mary J., and Michael L. Tushman (2015): Reflections on the 2013 Decade Award "Exploitation, Exploration, and Process Management: The Productivity Dilemma Revisited” Ten Years Later, in: Academy of Management Review, Vol. 40, NO. 4, pp. 497-518.

Berg, Justin M. (2016): Balancing on the Creative Highwire: Forecasting the Success of Novel Ideas in Organizations, in: Administrative Science Quarterly, Vol. 61, No. 3, pp. 433-468.

Birkinshaw, Julian, Gary Hamel and Michael J. Mol (2008): Management Innovation, in: Academy of Management Review, Vol. 33, No. 4, pp. 825-845.

Chang, Myong-Hun, and Joseph E. Harrington (2000): Centralization vs. Decentralization in a MultiUnit Organization: A Computational Model of a Retail Chain as a Multi-Agent Adaptive System, in: Management Science, Vol. 46, No. 11, pp. 1427-1440.

Chen, Gilad, Jiing-Lih Farh, Elizabeth M. Campbell-Bush, Zhiming Wu and Xin Wu (2013): Teams as innovative systems: Multilevel motivational antecedents of innovation in R\&D teams, in: Journal of Applied Psychology, Vol. 98, No. 6, pp. 1018-1027.

Cheng, Dolin, C. J., and Eelko K. R. E. Huizingh (2014): When Is Open Innovation Beneficial? The Role of Strategic Orientation, in: The Journal of Product Innovation Management, Vol. 31, No. 6, pp. 1235-1253.

Chib, Siddhartha, and Greenberg, Edward (1996): Markov Chain Monte Carlo simulation methods in econometrics, in: Econometric Theory, Vol. 12, No. 3, pp. 409-431. 
Christensen, Michael, and Thorbjørn Knudsen (2010): Design of Decision-Making Organizations, in: Management Science, Vol. 56, No. 1, pp. 71-89.

Coase, Ronald H. (1937): The Nature of the Firm, in: Economica, Vol. 4, No. 16, pp. 386-405.

Cowan, Robin, Nicolas Jonard, Jean-Benoit Zimmermann (2007): Bilateral Collaboration and the Emergence of Innovation Networks, in: Management Science, Vol. 53, No. 7, pp. 1051-1067.

Csaszar, Felipe A. (2012): Organizational Structure as a Determinant of Performance: Evidence from Mutual Funds, in: Strategic Management Journal, Vol. 33, pp. 611-632.

Csaszar, Felipe A. (2013): An Efficient Frontier in Organization Design: Organizational Structure as a Determinant of Exploration and Exploitation, in: Organization Science, Vol. 24, No. 4, pp. 10831101.

Csaszar, Felipe A., and J.P. Eggers (2013) Organizational Decision Making: An Information Aggregation View, in: Management Science, Vol. 59, No. 10, pp. 2257-2277.

Davis, Jason P., Kathleen M. Eisenhardt and Christopher B. Bingham (2009): Optimal Structure, Market Dynamism, and the Strategy of Simple Rules, in: Administrative Science Quarterly, Vol. 54, pp. 413-452.

Davis, Jason P., Kathleen M. Eisenhardt, and Christopher B. Bingham (2007): Developing Theory through Simulation Methods, in: The Academy of Management Review, Vol. 32, No. 2, pp. 480499.

De Bondt, Raymond (1997): Spillover and Innovative Activities, in: International Journal of Industrial Organization, Vol. 15, No. 1, pp. 1-28.

De Dreu, Carsten K. W., and Michael A. West (2001): Minority dissent and team innovation: The importance of participation in decision making, in: Journal of Applied Psychology, Vol. 86, No. 6, pp. 1191-1201.

DeCanio, Stephen J., Catherine Dibble and Keyvan Amir-Atefi (2000): The Importance of Organizational Structure for the Adoption of Innovations, in: Management Science, Vol. 46, No. 10, pp.1285-1299.

Ethiraj, Sendil K., and Daniel Levinthal (2004a): Modularity and Innovation in Complex Systems, in: Management Science, Vol. 50, No. 2, pp. 159-173.

Ethiraj, Sendil K., and Daniel Levinthal (2004b): Bounded Rationality and the Search for Organizational Architecture: An Evolutionary Perspective on the Design of Organizations and Their Evolvability, in: Administrative Science Quarterly, Vol. 49, No. 3, pp. 404-437.

Felin, Teppo, and Todd R. Zenger (2014): Closed or Open Innovation? Problem Solving and the Governance Choice, in: Research Policy, Vol. 43, No. 5, pp. 914-925.

Felin, Teppo, Nicolai J. Foss and Robert E. Ployhart (2015): The Microfoundations Movement in Strategy and Organization Theory, in: The Academy of Management Annals, Vol. 9, No. 1, pp. 575-632.

Foss, Nicolai J., and Siegwart Lindenberg (2012): Teams, Team Motivation, and the Theory of the Firm, in: Managerial and Decision Economics, Vol. 33, No. 5-6, pp. 369-383.

Foss, Nicolai J., and Siegwart Lindenberg (2013): Microfoundation for Strategy: A Goal-Framing Perspective on the Drivers of Value Creation, in: The Academy of Management Perspectives, Vol. 27, No. 2, pp. 85-102. 
Garicano, Luis, and Luis Rayo (2016): Why Organizations Fail: Models and Cases, in: Journal of Economic Literature, Vol. 54, No. 1, pp. 137-192.

Goldstein, Jeffrey (1999): Emergence as a Construct: History and Issues, in: Emergence, Vol. 1, No. 1, pp. 49-72.

Harhoff, Dietmar., Henkel, Joachim and von Hippel, Eric (2003): Profiting from voluntary information spillovers: how users benefit by freely revealing their innovations. Research Policy 32(10) 1753-1769

Harvey, Sarah (2014). Creative Synthesis: Exploring the Process of Extraordinary Group Creativity, in: Academy of Management Review, Vol. 39, No. 3, pp. 324-343.

Hewlett, Sylvia Ann, Melinda Marshall and Lora Sherbin (2013): How Diversity Can Drive Innovation, in: Harvard Business Review, December 2013.

Hielscher, Stefan, Markus Beckmann and Ingo Pies (2014): Participation versus Consent: Should Corporations Be Run according to Democratic Principles?, in: Business Ethics Quarterly, Vol. 24, No. 4, pp. 533-563.

Hodgkinson, Gerard P., and Mark P. Healey (2014): Coming in from the cold: The psychological foundations of radical innovation revisited, in: Industrial Marketing Management, Vol. 43, No. 8, pp. 1306-1313.

Jensen, Richard (1988): Information Cost and Innovation Adoption Policies, in: Management Science, Vol. 34, No. 2, pp. 230-239.

Keupp, Marcus Matthias, Maximilian Palmié and Oliver Gassmann (2012): The Strategic Management of Innovation: A Systematic Review and Paths for Future Research, in: International Journal of Management Reviews, Vol. 14, pp. 367-390.

Khanna, Rajat, Isin Guler and Atul Nerkar (2016): Fail Often, Fail Big, and Fail Fast? Learning from Small Failures and R\&D Performance in the Pharmaceutical Industry, in: Academy of Management Journal, Vol. 59, No. 2, pp. 436-459.

Knudsen, Thorbjørn, and Daniel A. Levinthal (2007): Two Faces of Search: Alternative Generation and Alternative Evaluation, in: Organization Science, Vol. 18, No. 1, pp. 39-54.

Knudsen, Thorbjørn, and Kannan Srikanth (2014): Coordinated Exploration: Organizing Joint Search by Multiple Specialists to Overcome Mutual Confusion and Joint Myopia, in: Administrative Science Quarterly, Vol. 59, No. 3, pp. 409-441.

Kreps, D. M. (1990). Corporate culture and economic theory. In J. E. Alt \& K. A. Shepsle (Eds.), Perspectives on positive political economy (pp. 90-143). Cambridge: Cambridge University Press.

Kultti, Klaus, Eeva Maring, Juuso Vanhala and Timo Vesala (2015): Adverse Selection in Dynamic Matching Markets, in: Bulletin of Economic Research, Vol. 67, No. 2, pp. 115-133.

Lindenberg, Siegwart (2015): From Individual Rationality to Socially Embedded Self-Regulation, in: Emerging Trends in the Sociall and Behavioral Sciences, edited by: Robert Scott and Stephen Kosslyn, John Wiley and Sons.

Lindenberg, Siegwart, and Nicolai J. Foss (2011): Managing Joint Production Motivation: The Role of Goal Framing and Governance Mechanisms, in: Academy of Management Review, Vol. 36, No. 3, pp. 500-525.

Lovelace, Kay, Debra L. Shapiro and Laurie R. Weingart (2001): Maximizing Cross-Functional New Product Teams' Innovativeness and Constraint Adherence: A Conflict Communications Perspective, in: Journal of Academy of Management, Vol. 44, No. 4, pp. 779-793. 
March, James G. (1991): Exploration and Exploitation in Organizational Learning, in: Organization Science, Vol. 2, No. 1, pp. 71-87.

Mellor, Robert B. (2003): Innovation management. Denmark: Forlaget Globe.

Mellor, Robert B. (2015a): Modelling the value of external networks for knowledge realisation, innovation, organisational development and efficiency in SMEs, in: International Journal of Knowledge-Based Development, Vol. 6, No. 1, pp. 3-14.

Mellor, Robert B. (2015b): Computer-Modelling the Innovation-Based Theory of the Firm. The proceedings of the European Conference on Knowledge Management (ECKM15) at Udine, Italy, 2-5 September 2015. ISBN: 9781910810460, pp. 532-540.

Mellor, Robert B. (2016): Computer modelling the costs of management control in the development of knowledge-based SMEs. International Journal of Knowledge-Based Development, Vol. 7, No. 4, pp 378-388.

Mellor, Robert B. (2018): Big data modelling the knowledge economy, in: International Journal of Knowledge-Based Development, Vol. 9, No. 3, pp. 206-220.

Mellor, Robert B. (2019): Entrepreneurship. In Mellor, R. B. (ed). Management for Scientists. pp 3348. Emerald Publishing Ltd, UK.

Michelsen, Johannes (1994): The Rationales of Cooperative Organizations - Some Suggestions from Scandinavia, in: Annals of Public and Cooperative Economics, Vol. 65, No. 1, pp. 13-34.

Miller, Gary J. (1992): Managerial Dilemmas - The Political Economy of Hierarchy, Cambridge University Press, Cambridge.

Miller, Gary J. (2008): Solutions to Principal-Agent Problems in Firms, in: Handbook of New Institutional Economics, edited by Claude Ménard and Mary M. Shirley, pp. 349-370, Springer, Berlin.

Moreno, Diego, and John Wooders (2016): Dynamic markets for lemons: Performance, liquidity, and policy intervention, in: Theoretical Economics, Vol. 11, No. 2, pp. 601-639.

Nickerson, Jack A., and Todd R. Zenger (2002): Being Efficiently Fickle: A Dynamic Theory of Organizational Choice, in: Organization Science, Vol. 13, No. 5, pp. 547-566.

O’Reilly III, Charles A., and Michael L. Tushman (2013): Organizational Ambidexterity: Past, Present, and Future, in: Academy of Management Perspectives, Vol. 27, No. 4, pp. 324-338.

Perry-Smith, Jill, and Pier Vittorio Mannucci (in press): From Creativity to Innovation: The Social Network Drivers of the Four Phases of the Idea Journey, in: Academy of Management Review.

Powell, Thomas C., Dan Lovallo and Craig R. Fox (2011): Behavioral Strategy, in: Strategic Management Journal, Vol. 32, No. 13, pp. 1369-1386.

Priem, Richard L., Sali Li and Jon C. Carr (2012): Insights and New Directions from Demand-Side Approaches to Technology Innovation, Entrepreneurship, and Strategic Management Research, in: Journal of Management, Vol. 38, No. 1, pp. 346-374.

Reagans, Ray, Ella Miron-Spektor and Linda Argote (2016): Knowledge Utilization, Coordination, and Team Performance, in: Organization Science, Vol. 27, No. 5, pp. 1108-1124.

Robinson, Stewart (2014): Simulation; the Practice of Model Development and Use, London, Palgrave Macmillan.

Rogers, Everett M. (1983): Diffusion of Innovations. The Free Press. New York. 
Sah, Raaj K., and Joseph E. Stiglitz (1985): Human Fallibility and Economic Organization, in: The American Economic Review, Vol. 75, No. 2, pp. 292-297.

Sah, Raaj K., and Joseph E. Stiglitz (1986): The Architecture of Economic Systems: Hierarchies and Polyarchies, in: American Economic Review, Vol. 76, No. 4, pp. 716-727.

Sawyer, R. Keith (2002): Durkheim's Dilemma: Toward a Sociology of Emergence, in: Sociological Theory, Vol. 20, No. 2, pp. 227-247.

Schelling, Thomas C. (1978, 2006): Micromotives and Macrobehavior, second, revised edition from 1978, W. W. Norton \& Co, New York.

Schneiberg, Marc (2011): Toward an Organizationally Diverse American Capitalism? Cooperative, Mutual, and Local, State-Owned Enterprise, in: Seattle University Law Review, Vol. 34, No. 4, pp. 1409-1434.

Schumpeter, Joseph A. (1942, 2003): Capitalism, Socialism and Democracy, Routledge, London.

Shavell, Steven (1979): On Moral Hazard and Insurance, in: The Quarterly Journal of Economics, November 1979, pp. 541-562.

Simon, Herbert. A. (1982): Models of Bounded Rationality. Volume 1: Economic Analysis and Public Policy, Volume 2: Behavioural Economics and Business Organization, 1982, Cambridge, MA: MIT Press. 478, 505 pages.

Shelanski, Howard A., and Peter G. Klein (1995): Empirical Research in Transaction Cost Economics: A Review and Assessment, in: Journal of Law, Economics, \& Organization, Vol. 11, No. 2, pp. 335-361.

Sheremata, Willow A. (2004): Competing Through Innovation in Network Markets: Strategies for Challenges, in: Academy of Management Review, Vol. 29, NO. 3, pp. 359-377.

Slater, Stanley F., Jakki J. Mohr and Sanjit Sengupta (2013): Radical Product Innovation Capability: Literature Review, Synthesis, and Illustrative Research Propositions, in: The Journal of Product Innovation Management, Vol. 31, No. 3, pp. 552-566.

Stevens, Greg A., and James Burley (1997): 3,000 Raw Ideas = 1 Commercial Success!, in: ResearchTechnology Management, Vol. 40, No. 3, pp. 16-27.

Subramanian, A., and S. Nilakantha (1996): Organizational innovativeness: Exploring the relationship between organizational determinants of innovation, types of innovations, and measures of organizational performance, in: Omega, Vol. 24, No. 6, pp. 631-647.

Sydow, Jörg, Georg Schreyögg, and Jochen Koch (2009): Organizational Path Dependence: Opening the Black Box, in: The Academy of Management Review, Vol. 34, No. 4, pp. 689-709.

USCB (2016) Annual Survey of Entrepreneurs (ASE). Available at https://www.census.gov/programssurveys/ase/data/tables.html

Utterback, James M. (1994) Mastering the dynamics of innovation. Harvard Business School Press.

Valentinov, Vladislav, Stefan Hielscher and Ingo Pies (2015): Nonprofit organizations, institutional economics, and systems thinking, in: Economic Systems, Vol. 39, pp. 491-501.

Van der Panne, Gerben, Cees van Beers, and Alfred Kleinknecht (2003): Success and Failure of Innovation: A Literature Review, in: International Journal of Innovation Management, Vol. 7, No. 3, pp. 1-30. 
Vargas-Hernández, José G (2011): Modelling Risk and Innovation Management, in: Advances in Competitiveness Research, Vol. 19, No. 3-4, pp. 45-57.

West, Joel, and Marcel Bogers (2013): Leveraging External Sources of Innovation: A Review of Research on Open Innovation, in: The Journal of Product Innovation Management, Vol. 31, No. 4, pp. 814-831.

Will, Matthias Georg (2015): Successful organizational change through win-win, in: Journal of Accounting \& Organizational Change, Vol. 11, No. 2, pp. 193-214.

Will, Matthias Georg, Mousa Al-Kfairy and Robert B Mellor (2017a): Innovative Behaviour, Organizational Structures and Corporate Performance. Academy of Management Proceedings. https://journals.aom.org/doi/10.5465/AMBPP.2017.11303abstract

Will, Matthias Georg, Steffen Roth and Vladislav Valentinov (2017b): From Nonprofit Diversity to Organizational Multifunctionality: A Systems-Theoretical Proposal, in: Administration \& Society, online first.

Wolter, Claudio, and Francisco M. Veloso (2008): The Effects of Innovation on Vertical Structure: Perspectives on Transaction Cost and Competencies, in: Academy of Management Review, Vol. 33, No. 3, pp. 586-605.

Yarow, Jay (2015): Google just announced a massive overhaul of its business structure, in: Business Insider, 2015-08-10, http://www.businessinsider.com/google-new-operating-structure-20158?IR=T, 2015-12-15.4

Young-Hyman, Trevor (2016): Cooperating without Co-laboring: How Formal Organizational Power Moderates Cross-functional Interaction in Project Teams, in: Administrative Science Quarterly, online first, pp. 1-36. 


\section{Appendix: Table A: Regression analysis results}

Innovations with Incrementa Effects

\begin{tabular}{|c|c|c|c|c|c|c|c|c|}
\hline \multirow{2}{*}{$\begin{array}{l}\text { Variable } \\
\text { Innovation Mean } \\
\text { Constant }\end{array}$} & \multirow{2}{*}{$\begin{array}{ll}\text { Polyarchy } & \\
& \\
500 & * * * \\
0.0287 & \\
\end{array}$} & \multirow{2}{*}{$\begin{array}{l}\text { Polyarchy (with } \\
\text { Assessment) }\end{array}$} & \multicolumn{2}{|c|}{$\begin{array}{l}\text { Hierarchy (1 } \\
\text { Level Hierarchy) }\end{array}$} & \multicolumn{2}{|c|}{$\begin{array}{l}\text { Hierarchy (2 } \\
\text { Level Hierarchy) }\end{array}$} & \multicolumn{2}{|c|}{$\begin{array}{l}\text { Hierarchy ( } 3 \\
\text { Level Hierarchy) }\end{array}$} \\
\hline & & & $\begin{array}{l}248 \\
1.60 \mathrm{E}+03\end{array}$ & & $\begin{array}{l}166 \\
1.60 \mathrm{E}+03\end{array}$ & $\begin{array}{l}* * * \\
* * *\end{array}$ & $\begin{array}{l}125 \\
1.40 \mathrm{E}+03\end{array}$ & $\begin{array}{l}* * * \\
* * *\end{array}$ \\
\hline $\begin{array}{l}\text { Number of Obs } \\
\text { R-squared } \\
\text { Adj R-squared } \\
\text { F-Test } \\
\text { Log Likelihood }\end{array}$ & $\begin{array}{l}1000 \\
0.998 \\
0.998 \\
4.90 \mathrm{E}+05 \\
-7.00 \mathrm{E}+03 \\
\end{array}$ & & $\begin{array}{l}1000 \\
0.849 \\
0.8488 \\
5.60 \mathrm{E}+03 \\
-8.50 \mathrm{E}+03 \\
\end{array}$ & & $\begin{array}{l}1000 \\
0.6934 \\
0.6931 \\
2.30 \mathrm{E}+03 \\
-8.60 \mathrm{E}+03 \\
\end{array}$ & & $\begin{array}{l}1000 \\
0.5463 \\
0.5458 \\
1.20 \mathrm{E}+03 \\
-8.60 \mathrm{E}+03 \\
\end{array}$ & \\
\hline
\end{tabular}

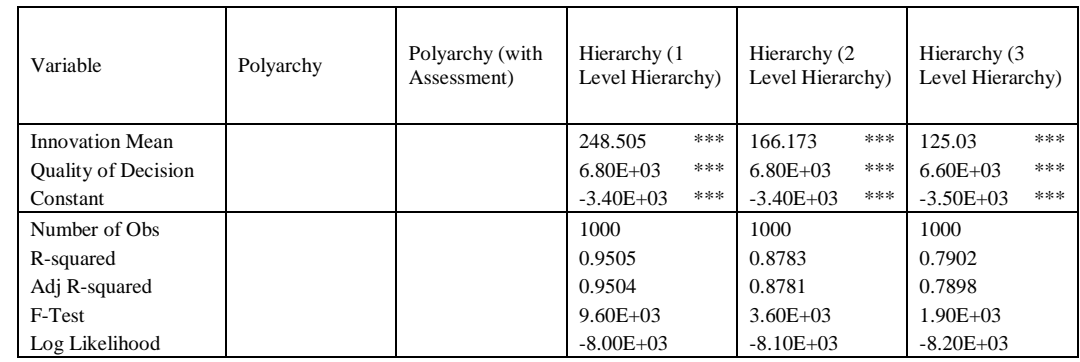

Innovations with Spillover Effects

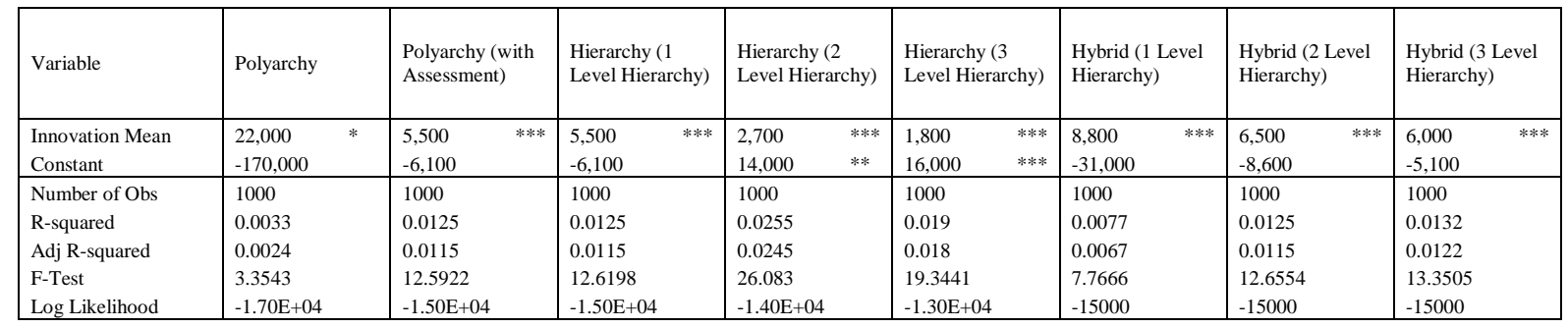

\begin{tabular}{|c|c|c|c|c|c|c|c|c|c|c|}
\hline Variable & $\begin{array}{l}\text { Polyarchy (with } \\
\text { Assessment) }\end{array}$ & $\begin{array}{l}\text { Polyarchy (with } \\
\text { Assessment) }\end{array}$ & $\begin{array}{l}\text { Hierarchy (1 } \\
\text { Level Hierarchy) }\end{array}$ & $\begin{array}{l}\text { Hierarchy } \\
\text { Level Hier }\end{array}$ & & $\begin{array}{l}\text { Hierarchy } \\
\text { Level Hier }\end{array}$ & & $\begin{array}{l}\text { Hybrid (1 Level } \\
\text { Hierarchy) }\end{array}$ & $\begin{array}{l}\text { Hybrid (2 Level } \\
\text { Hierarchy) }\end{array}$ & $\begin{array}{l}\text { Hybrid (3 Level } \\
\text { Hierarchy) }\end{array}$ \\
\hline $\begin{array}{l}\text { Innovation Mean } \\
\text { Quality of Decision } \\
\text { Coordination Costs } \\
\text { Constant }\end{array}$ & & $\begin{array}{ll}5,600 & * * * \\
-12,000 & \\
5,300 & \\
-23,000 & \\
\end{array}$ & $\begin{array}{ll}5,600 & * * * \\
-12,000 & \\
5,300 & \\
-23,000 & \\
\end{array}$ & $\begin{array}{l}2,500 \\
74,000 \\
-5,400 \\
-14,000 \\
\end{array}$ & $\begin{array}{l}* * * \\
* \\
* * * \\
\end{array}$ & $\begin{array}{l}1,700 \\
78,000 \\
-6,200 \\
-12,000 \\
\end{array}$ & $\begin{array}{l}* * * \\
* * \\
* * *\end{array}$ & $\begin{array}{lll}9,200 & * * * \\
-130,000 & \\
18,000 & \\
-26,000 & \\
\end{array}$ & $\begin{array}{ll}6,600 & * * * \\
-23,000 & \\
6,700 & \\
-25,000 & \\
\end{array}$ & $\begin{array}{ll}6,100 & * * * \\
-13,000 & \\
4,900 & \\
-20,000 & \\
\end{array}$ \\
\hline $\begin{array}{l}\text { Number of Obs } \\
\text { R-squared } \\
\text { Adj R-squared } \\
\text { F-Test } \\
\text { Log Likelihood }\end{array}$ & & $\begin{array}{l}1000 \\
0.0132 \\
0.0102 \\
4.442 \\
-1.50 \mathrm{E}+04 \\
\end{array}$ & $\begin{array}{l}1000 \\
0.0132 \\
0.0103 \\
4.4508 \\
-1.50 \mathrm{E}+04 \\
\end{array}$ & $\begin{array}{l}1000 \\
0.0351 \\
0.0322 \\
12.0646 \\
-1.40 \mathrm{E}+04 \\
\end{array}$ & & $\begin{array}{l}1000 \\
0.0379 \\
0.035 \\
13.0805 \\
-1.30 E+04\end{array}$ & & $\begin{array}{l}1000 \\
0.0102 \\
0.0072 \\
3.4104 \\
-15000 \\
\end{array}$ & $\begin{array}{l}1000 \\
0.0134 \\
0.0104 \\
4.5153 \\
-15000 \\
\end{array}$ & $\begin{array}{l}1000 \\
0.0138 \\
0.0108 \\
4.6418 \\
-15000 \\
\end{array}$ \\
\hline
\end{tabular}

Innovations Requiring Critical

Mass

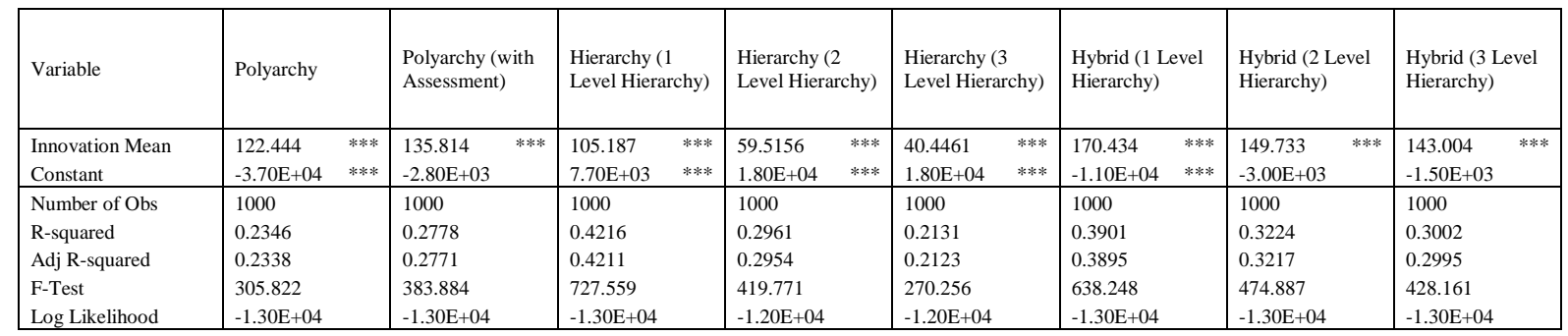




\begin{tabular}{|c|c|c|c|c|c|c|c|c|c|c|c|c|c|c|c|}
\hline \multirow{2}{*}{$\begin{array}{l}\text { Variable } \\
\text { Innovation Mean }\end{array}$} & Polyarchy & \multicolumn{2}{|c|}{$\begin{array}{l}\text { Polyarchy (with } \\
\text { Assessment) }\end{array}$} & \multicolumn{2}{|c|}{$\begin{array}{l}\text { Hierarchy (1 } \\
\text { Level Hierarchy) }\end{array}$} & \multicolumn{2}{|c|}{$\begin{array}{l}\text { Hierarchy (2 } \\
\text { Level Hierarchy) }\end{array}$} & \multicolumn{2}{|c|}{$\begin{array}{l}\text { Hierarchy ( } 3 \\
\text { Level Hierarchy) }\end{array}$} & \multicolumn{2}{|c|}{$\begin{array}{l}\text { Hybrid (1 Level } \\
\text { Hierarchy) }\end{array}$} & \multicolumn{2}{|c|}{$\begin{array}{l}\text { Hybrid (2 Level } \\
\text { Hierarchy) }\end{array}$} & \multicolumn{2}{|c|}{$\begin{array}{l}\text { Hybrid (3 Level } \\
\text { Hierarchy) }\end{array}$} \\
\hline & & 138.788 & $* * *$ & 106.995 & $* * *$ & 60.7472 & $* * *$ & 41.4393 & $* * *$ & 173.576 & $* * *$ & 152.813 & $* * *$ & 146.022 & $* * *$ \\
\hline Quality of Decision & & $2.10 \mathrm{E}+05$ & $* * *$ & $1.70 \mathrm{E}+05$ & $* * *$ & $1.30 \mathrm{E}+05$ & $* * *$ & $1.10 \mathrm{E}+05$ & $* * *$ & $2.20 \mathrm{E}+05$ & $* * *$ & $2.20 \mathrm{E}+05$ & $* * *$ & $2.10 \mathrm{E}+05$ & $* * *$ \\
\hline Coordination Costs & & $3.00 \mathrm{E}+03$ & $* *$ & $-2.60 \mathrm{E}+03$ & $* * *$ & $-3.90 \mathrm{E}+03$ & $* * *$ & $-3.70 \mathrm{E}+03$ & $* * *$ & $3.30 \mathrm{E}+03$ & $* * *$ & $2.80 \mathrm{E}+03$ & $* *$ & $2.80 \mathrm{E}+03$ & $* *$ \\
\hline Critical Mass & & $3.10 \mathrm{E}+04$ & $* *$ & $-3.80 \mathrm{E}+04$ & $* * *$ & $-4.90 \mathrm{E}+04$ & $* * *$ & $-4.60 \mathrm{E}+04$ & $* * *$ & $2.70 \mathrm{E}+04$ & $* *$ & $2.70 \mathrm{E}+04$ & $* *$ & $2.70 \mathrm{E}+04$ & $* *$ \\
\hline Constant & & $-1.90 \mathrm{E}+05$ & $* * *$ & $-8.40 \mathrm{E}+04$ & $* * *$ & $-3.60 \mathrm{E}+04$ & $* * *$ & $-2.30 \mathrm{E}+04$ & $* * *$ & $-2.00 \mathrm{E}+05$ & $* * *$ & $-1.90 \mathrm{E}+05$ & $* * *$ & $-1.90 \mathrm{E}+05$ & $* * *$ \\
\hline Number of Obs & & 1000 & & 1000 & & 1000 & & 1000 & & 1000 & & 1000 & & 1000 & \\
\hline R-squared & & 0.3272 & & 0.5135 & & 0.4802 & & 0.4412 & & 0.4392 & & 0.3726 & & 0.3494 & \\
\hline Adj R-squared & & 0.3245 & & 0.5115 & & 0.4781 & & 0.4389 & & 0.437 & & 0.3701 & & 0.3468 & \\
\hline F-Test & & 120.955 & & 262.543 & & 229.798 & & 196.395 & & 194.822 & & 147.724 & & 133.612 & \\
\hline Log Likelihood & & $-1.30 \mathrm{E}+04$ & & $-1.20 \mathrm{E}+04$ & & $-1.20 \mathrm{E}+04$ & & $-1.20 \mathrm{E}+04$ & & $-1.30 \mathrm{E}+04$ & & $-1.30 \mathrm{E}+04$ & & $-1.30 \mathrm{E}+04$ & \\
\hline
\end{tabular}

Note: The stars indicate the following significance levels: $*<0.1, * *<0.05$ and $* * *<0.01$. Own calculations. 